\title{
Interplay between endoplasmic reticulum stress and non-coding RNAs in cancer
}

\author{
Tianming Zhao, Juan Du and Hui Zeng ${ }^{*}$ (])
}

\begin{abstract}
To survive, cancer cells are subjected to various internal and external adverse factors, including genetic mutations, hypoxia, nutritional deficiencies, and drug toxicity. All of these factors result in the accumulation of unfolded proteins in the endoplasmic reticulum, which leads to a condition termed endoplasmic reticulum stress (ER stress) and triggers the unfolded protein response (UPR). UPR downstream components strictly control transcription and translation reprogramming to ensure selective gene expression, including that of non-coding RNA (ncRNAs), to adapt to adverse environments. NcRNAs, including microRNAs (miRNAs), long non-coding RNAs (IncRNAs), and circular RNAs (circRNAs), play important roles in regulating target gene expression and protein translation, and their aberrant expression is related to tumor development. Dysregulation of ncRNAs is involved in the regulation of various cellular characteristics of cancer cells, including growth, apoptosis, metastasis, angiogenesis, drug sensitivity, and tumor stem cell properties. Notably, ncRNAs and ER stress can regulate each other and collaborate to determine the fate of tumor cells. Therefore, investigating the interaction between ER stress and ncRNAs is crucial for developing effective cancer treatment and prevention strategies. In this review, we summarize the ER stress-triggered UPR signaling pathways involved in carcinogenesis followed by the mutual regulation of ER stress and ncRNAs in cancer, which provide further insights into the understanding of tumorigenesis and therapeutic strategies.
\end{abstract}

Keywords: ER stress, UPR, ncRNAs, Cancer, Interplay

\section{Introduction}

The endoplasmic reticulum (ER), a multifunctional organelle, is involved in regulating fundamental cellular processes, including nascent protein folding and modification, calcium storage, liquid biosynthesis, and detoxification. Unfavorable external and internal factors, such as hypoxia, nutrient deprivation, drug-induced toxicity, acidic extracellular $\mathrm{pH}$, and genetic mutation, result in unfolded or misfolded protein accumulation in the ER lumen. Under these conditions, tumor cells trigger endoplasmic reticulum stress (ER stress) to reestablish intracellular homeostasis and promote cell survival. This self-adaptive response process is called the unfolded

*Correspondence: androps2011@hotmail.com Department of Hematology, The First Affiliated Hospital of Jinan University, Guangzhou 510632, Guangdong, China protein response (UPR), which aims to restore protein homeostasis $[1,2]$. If these unfavorable factors persistently exist and cells fail to achieve self-adaptation, the ER-related apoptotic pathway is initiated [3, 4]. Briefly, there are three transmembrane sensor proteins located on the ER membrane involved in the UPR, including inositol-requiring enzyme 1 (IRE1), protein kinase RNAlike ER kinase (PERK), and activating transcription factor 6 (ATF6). In the absence of unfolded proteins, a $78 \mathrm{kDa}$ glucose-regulated protein (GRP78, also known as Bip) binds to these sensor proteins and lock them in an inactive state. Once ER stress occurs, GRP78 dissociates from the ER membrane enzymes, resulting in their activation, and initiates the downstream UPR signaling pathway [5, $6]$.

Non-coding RNAs (ncRNAs) are abundant RNA transcripts without protein-coding potential that play an original author(s) and the source, provide a link to the Creative Commons licence, and indicate if changes were made. The images or other third party material in this article are included in the article's Creative Commons licence, unless indicated otherwise in a credit line to the material. If material is not included in the article's Creative Commons licence and your intended use is not permitted by statutory regulation or exceeds the permitted use, you will need to obtain permission directly from the copyright holder. To view a copy of this licence, visit http://creativecommons.org/licenses/by/4.0/. The Creative Commons Public Domain Dedication waiver (http://creativeco mmons.org/publicdomain/zero/1.0/) applies to the data made available in this article, unless otherwise stated in a credit line to the data. 
important role in the biological regulation process. It is reported that approximately $75 \%$ of the human genome is transcribed into ncRNAs based on the data in the Encyclopedia of DNA elements (ENCODE) project [7, 8]. MicroRNAs (miRNAs), long non-coding RNAs (lncRNAs), and circular RNAs (circRNAs) are the three important ncRNA species. MiRNAs are small RNAs with a length of 19-24 nucleotides, which inhibit translation or induce the degradation of messenger RNA (mRNA) by binding to the $3^{\prime}$-untranslated region (UTR) of target mRNA [9]. LncRNAs are greater than 200 nucleotides in length. They function to regulate the expression of some genes, form sponges with miRNAs, bind with RNA-binding proteins to reach regulatory sites, and be a central platform for assembling other molecules [10]. CircRNAs are single-stranded closed non-coding RNA molecules whose structure and function have been extensively studied in recent years [11]. The ncRNAs exert a wide range of biological regulatory functions, such as modulation of transcription, controlling the synthesis of specific proteins, and binding with specific regions of DNA to activate or inhibit basic processes of gene regulation [12]. Accumulating evidence has indicated that ncRNAs are dysregulated in tumors and involved in the processes of tumor initiation, metastasis, and drug resistance [13-16]. Indeed, alterations in ncRNAs processing in cancer are commonly reported, and potential mechanisms of the ncRNAs subtypes involved in tumorigenesis have been explored. Tumorigenesis can be controlled by either a single ncRNA or an interconnected regulatory network controlled by multiple ncRNAs [17-19]. Findings about ncRNAs are being actively translated into clinical practice. Some miRNAs that are stable in the blood could be the basis for accurate and sensitive screening for major cancers [20]. Clinical trials with drugs based on miRNAs have been initiated for different diseases [21]. In addition, some ncRNAs have been reported as biomarkers for the diagnosis and prognosis of disease or as novel therapeutic targets for cancer intervention [22-24].

Recently, a close functional relationship between ER stress and ncRNAs, including miRNAs, IncRNAs and circRNAs, has been reported. Cross-talk between ER stress and ncRNAs has been reported in cancer development, and determining the nature of this connection has important implications for developing effective strategies for controlling tumors. Intriguingly, certain specific ncRNAs could regulate the UPR signaling pathway, and UPR downstream components in turn bind to the promoter region of ncRNAs to promote their transcription [25, 26]. In this review, we summarize the ER stress-triggered UPR signaling pathways involved in carcinogenesis and discussed the mutual regulation of ER stress and ncRNAs (miRNAs, lncRNAs, and circRNAs) in cancer.

\section{Three UPR signaling pathways are involved in carcinogenesis}

To remain in a highly proliferative state, cancerous cells consume a great deal of substances, and these cells often perform aerobic glycolysis to support malignant expansion and develop a unique cancer microenvironment [27]. However, tumor cells can adapt to this harsh microenvironment by initiating ER stress. The UPR has three branched pathways, including the IRE1 $\alpha$, PERK, and ATF6 pathways (Fig. 1). Hyperactivation of these pathways have been reported to be involved in a wide range of human hematopoietic and solid tumors $[28,29]$.

\section{IRE1a-XBP1 pathway}

IRE1 $\alpha$ is the first specific sensor found to initiate ER stress, with serine and threonine protein kinase activity at its $\mathrm{N}$-terminus and RNA endonuclease activity at its C-terminus [30]. When ER stress occurs, dimeric IRE-1 (IRE- $1 \alpha$ and IRE-1 $\beta$ ) undergoes conformational changes, resulting in autophosphorylation of IRE1 and activation of the IRE- $1 \alpha$ endonuclease. Active IRE $1 \alpha$ cleaves a 26-nucleotide intron from X-box binding protein-1 (XBP1) mRNA [31]. This spliced XBP1 (XBP1s) binds to various stress response gene promoters, which inhibits the expression of stress response proteins, upregulates the expression of proteins involved in protein folding and degradation, and promotes the correct folding of unfolded proteins and degradation of misfolded proteins, termed endoplasmic reticulum-associated degradation (ERAD) [30]. Activated IRE1 $\alpha$ also interacts with TNF receptor-associated factor 2 (TRAF2) to activate downstream apoptosis signal-regulating kinase 1 (ASK1) and c-JUN amino-terminal kinase (JNK), resulting in increased apoptosis under prolonged UPR signaling [32, 33]. C-JUN may be a potential target for the design of antitumor drugs [34].

The IRE1 $\alpha$-XBP1s pathway is a highly evolutionarily conserved signaling pathway and is activated in tumor and immune cells [35-39]. RNA sequencing analysis revealed that IRE1 $\alpha$-XBP1s pathway activity is required for MYC signaling, which is a central oncogenic regulatory pathway in prostate cancer [40], building a direct connection between the UPR and oncogene activation. XBP1 promoted natural killer (NK) cell expansion in part by directly binding and activating the MYC promoter, which subsequently upregulated key MYC target genes required for NK cell expansion [39]. This novel IRE1 $\alpha /$ XBP1/MYC axis in NK cells provided a new insight for host protection against NK cell-sensitive cancer. Interestingly, MYC transcriptionally regulates the expression of IRE1 in breast cancer [41]. This means that the IRE1-XBP1 signaling interacts with the presence of MYC hyperactivation. High expression levels of XBP1 are 


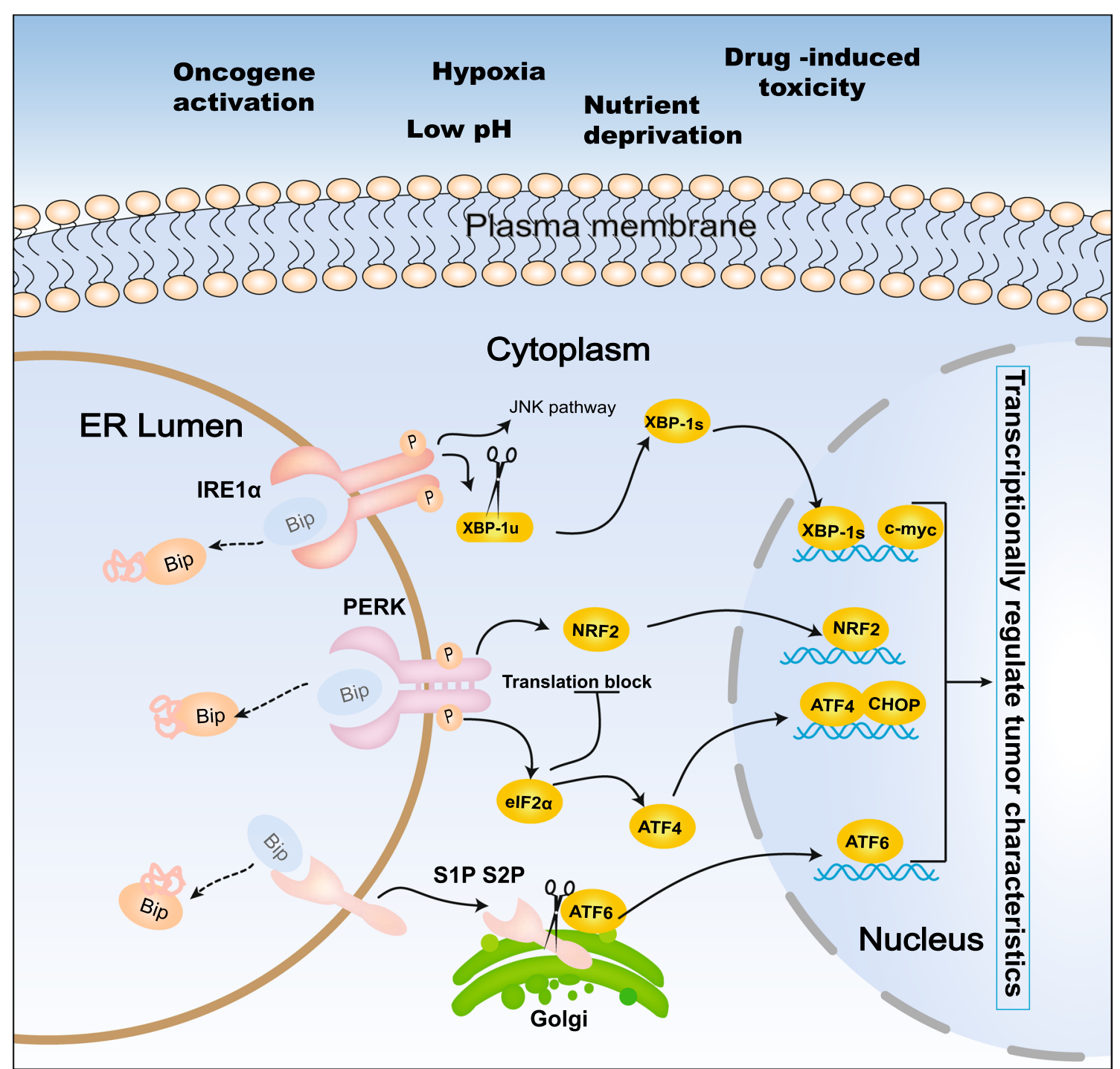

Fig. 1 Role of the unfolded protein response (UPR) in cancer. Cancer cells frequently encounter intrinsic and extrinsic stresses that disturb protein folding in the endoplasmic reticulum (ER), including oncogene activation, hypoxia, nutrient deprivation, drug-induced toxicity, and low $\mathrm{pH}$, which trigger ER stress to reestablish intracellular homeostasis. Upon detecting an accumulation of ER unfolded and misfolded proteins, the UPR is initiated by three transmembrane ER proteins: inositol-requiring enzyme 1(IRE1), protein kinase RNA-like ER kinase (PERK), and activating transcription factor 6 (ATF6). Once ER stress occurs, Bip dissociates from these three ER membrane enzymes, resulting in their activation and initiating the relevant downstream signaling pathway. Activation of the UPR can transcriptionally regulate tumor characteristics

significantly associated with poor outcomes in human tumors, including prostate cancer [40], oral squamous cell carcinoma (OSCC) [42], hepatocellular carcinoma (HCC) [43], osteosarcoma [44], myeloma [45]. However, bortezomib (a proteasome inhibitor) is more effective in patients with high XBP1 expression. High XBP1 suggests a better prognosis in bortezomib-treated multiple myeloma [46]. Nonetheless, XBP1 promotes the progression of triple-negative breast cancer (TNBC) through synergy with hypoxia inducible factor- 1 alpha (HIF $1 \alpha)$ to support tumor-initiating cell function and the metastatic ability of cancer cells under adverse environmental conditions [35]. Inhibition of IRE1-XBP1 signaling may suppress tumor initiation, progression, and metastasis and overcome drug resistance [35, 47].

\section{PERK-elF2a pathway}

Under physiological conditions, the transmembrane protein PERK binds to Bip and maintains an inactive state. PERK is activated upon dissociation from 
Bip, resulting in phosphorylation of eukaryotic initiation factor $2 \alpha$ (eIF2 $\alpha)$, which is essential for reducing the protein load in the endoplasmic reticulum [48]. At the same time, activation of PERK also upregulates the translation of activating transcription factor 4 (ATF4) mRNA, a member of the CCAAT/enhancer-binding protein $(\mathrm{C} / \mathrm{EBP})$ family that induces the increased expression of protein transport-related genes after entering the nucleus [48]. ATF4 also activates the transcription of C/EBP homologous proteins (CHOP). A combination of ATF4 and CHOP upregulate protein transcription of growth arrest and DNA damageinducible protein 34 (GADD34), which in turn leads to dephosphorylation of eIF2 $\alpha$ to restore the expression of protective proteins. Notably, activation of the ATF4CHOP induces the apoptotic pathway when cell damage exceeds the UPR processing capacity $[49,50]$. In addition, eIF $2 \alpha$ induces abnormal activation of nuclear factor- $\mathrm{kB}$ (NF- $\mathrm{k} B$ ) to inhibit the expression of apoptosis-related proteins [51]. PERK activation rapidly and directly phosphorylates nuclear factor-erythroid 2-related factor 2 (NRF2) to promote cell survival and induce resistance to ER stress and chemosensitivity [52, 53].

A series of stressful conditions that are unfavorable for tumor growth may trigger disruption of ER homeostasis and lead to ER stress, further activating the PERKeIF2 $\alpha$ branch of the UPR, which may contribute tumor cells adapting to harsh environmental conditions. For example, under low glucose metabolism stress, PERK activation induces glioma cell survival through AKT activation. PERK-silenced glioma cells show decreased tumor formation capacity [54]. The PERK/eIF2 $\alpha$ branch and its downstream components also play a pivotal role in regulating autophagy to promote cancer cell survival. Moreover, in cancer cells, hypoxia can upregulate PERK to induce the expression of autophagy-related molecules, indicating the role of PERK in promoting autophagy and cancer development [55]. Furthermore, MYC expression is associated with a sharp increase in PERK activity in human lymphoma. MYC-expressing cells appear to be completely reliant on PERK-dependent autophagy [56]. PERK activation has been also implicated in tumor invasiveness. It has been confirmed that PERK is involved in distant breast cancer metastasis via regulation of the downstream mediator CREB3L1 [57]. In addition, overexpression of ATF4, a downstream molecule in the PERK pathway, stimulated the expression of matrix metalloproteinases (MMPs) MMP2 and MMP7 to induce invasion and metastasis in esophageal squamous cell carcinoma [58]. Moreover, current evidence suggests that forkhead box $\mathrm{O}$ class protein 3 (FOXO3) can directly regulate PERK expression. Deletion of FOXO3 significantly reduced PERK expression and enhanced sensitivity to a PERK inhibitor in breast cancer [59].

\section{ATF6a pathway}

ATF6, a member of the leucine zipper transcription factor family, is a transmembrane protein on the endoplasmic reticulum that is an important regulator involved in apoptosis and autophagy in ER stress [60]. ATF6 has two homologs, ATF6 $\alpha$ and ATF6 $\beta$, which are expressed in mammalian cells. Upon ER stress, ATF6 $\alpha$ is transferred to the Golgi and processed by site-1 protease (S1P), and S2P to generate cleaved ATF6 $\alpha$, its active form. This active ATF $6 \alpha$ acts as a transcription factor into the nucleus and regulates gene expression by the ATF-cAMP response element or ER stress response element (ERSE). In addition, ATF $6 \alpha$ can also bind to UPR elements, activating CHOP $[61,62]$.

Due to the major pro-survival role of ATF6, its expression level has been shown to be significantly upregulated in various cancer types [63-66]. Higher expression level of ATF6 has been closely correlated with cancer metastasis and recurrence $[67,68]$ and served as a prognostic indicator of cancer [69]. For instance, ER stress-related ATF6 upregulated cancerous inhibitor of protein phosphatase 2A (CIP2A), which contributes to colon cancer cell survival and indicates a trend toward poor prognosis [69]. In addition, ATF6 has also been shown to confer poorer response to chemotherapy. Knockdown of ATF6 or pharmacological inhibition of its downstream targets have better sensitivity to chemotherapy [70, 71]. Missense mutations in TP53 enhance ATF6 activity and coordinate with inhibition of the pro-apoptotic factors JNK and CHOP, which are necessary for viability and invasion [72]. Overall, ATF6 plays a crucial role in promoting tumor progression and may be a promising therapeutic target, although no specific inhibitors have been identified yet.

\section{ER stress regulates ncRNAs expression}

It has been reported that ER stress affects the expression of miRNAs and lncRNAs, but there have been no reports on circRNAs. Therefore, whether and how ER stress regulate circRNAs expression need to be further investigated.

\section{ER stress influences miRNAs expression}

The expression of several miRNAs has been demonstrated to be altered by ER stress in response to adverse conditions (Table 1, Fig. 2a). Wang et al. reported that the expression levels of miR-214, miR-199a-3p, and miR199a-5p were significantly reduced in HCC cells treated with an ER stress inducer and exposure to anoxia. Low expression of miR-214 relieves the inhibitory effect on 
Table 1 ER stress-regulated miRNAs and their potential roles in cancers

\begin{tabular}{|c|c|c|c|c|c|}
\hline Effectors & Regulators & Targets & Cancer type & Biological process & References \\
\hline miR-214 & NA & $\mathrm{XBP}-1$ & $\mathrm{HCC}$ & Regulates HCC cell proliferation and apoptosis & {$[73]$} \\
\hline miR-199a-3p/5p & NA & NA & $\mathrm{HCC}$ & NA & {$[73]$} \\
\hline miR-1281 & NA & USP93 & Osteosarcoma & Promotes ER stress-mediated apoptosis & {$[75]$} \\
\hline $\operatorname{miR}-34 a$ & IRE1a & MYC, cyclin D1, CDK4 & $\mathrm{AML}$ & $\begin{array}{l}\text { Inhibition of IRE1a increases expression of miR-34a in AML } \\
\text { cells }\end{array}$ & {$[78]$} \\
\hline miR-216b & PERK & c-Jun & Osteosarcoma & Sensitizes cells to ER stress-dependent apoptosis & {$[79]$} \\
\hline miR-211 & PERK & $\mathrm{CHOP}$ & Osteosarcoma & $\begin{array}{l}\text { Inhibits circadian rhythm oscillations and ongoing protein } \\
\text { synthesis }\end{array}$ & {$[81]$} \\
\hline $\operatorname{miR}-211$ & PERK & $\mathrm{CHOP}$ & Mammary tumors & Regulates ER stress-dependent apoptosis & {$[84]$} \\
\hline miR-663 & NA & ZBTB7A & Osteosarcoma & Regulates ER stress-induced cell apoptosis & {$[88]$} \\
\hline $\operatorname{miR}-23 a-3 p$ & NA & PTEN AKT & $\mathrm{HCC}$ & $\begin{array}{l}\text { Upregulates macrophage PD-L1 expression and inhibits T cell } \\
\text { function, which promotes tumor cells to escape immune } \\
\text { surveillance }\end{array}$ & {$[115]$} \\
\hline miR-765 & NA & FOXA2 & Melanoma & Enhances tumor stem cell renewal and apoptosis inhibition & {$[120]$} \\
\hline miR-663 & NA & TGFB1 & $\mathrm{HCC}$ & Regulates ER stress-induced apoptosis & {$[184]$} \\
\hline $\operatorname{miR}-221 / 222$ & NA & NA & $\mathrm{HCC}$ & Promotes ER stress-mediated apoptosis & [185] \\
\hline miR-346 & XBP1 & TAP1 & Cervical cancer & Reduces MHC class I-associated antigen presentation & {$[186]$} \\
\hline
\end{tabular}

NA, not available; HCC, hepatocellular carcinoma; AML, acute myeloid leukemia

a

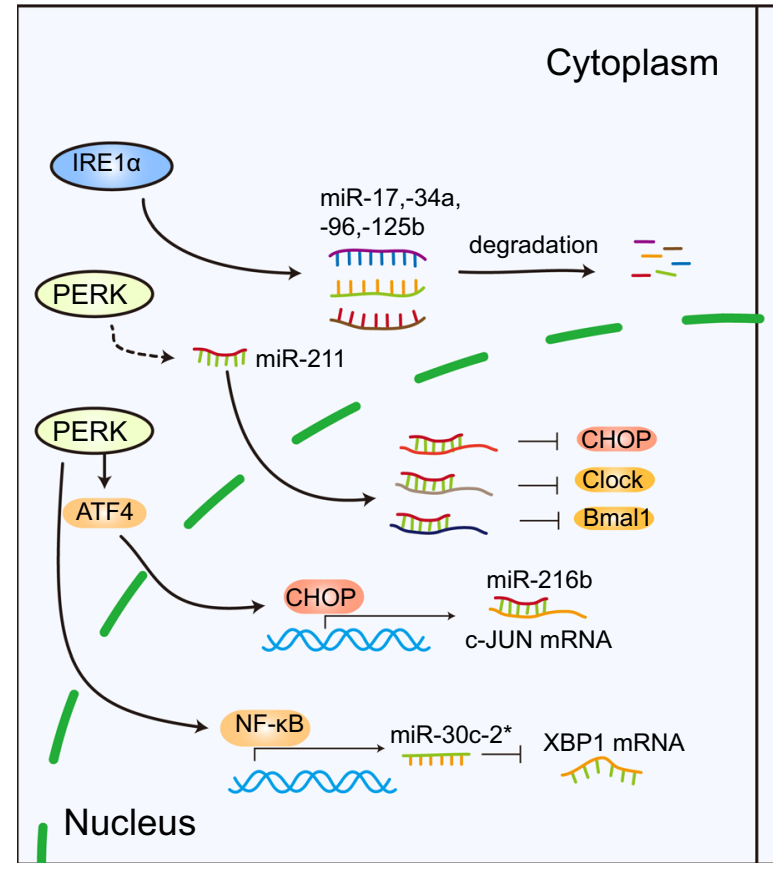

b

\section{Cytoplasm}

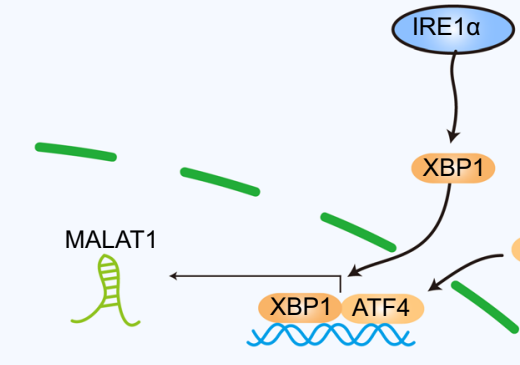

PERK

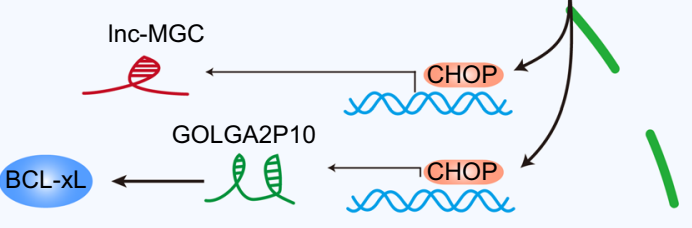

Nucleus

Fig. 2 ER stress regulates miRNAs and IncRNAs expression. a Sustained IRE1 a RNase resulted in rapid degradation of miR-17, miR-34a, miR-96, and miR-125b. PERK-induced miR-211 inhibits CHOP, Bmal1, and Clock in tumor cells. PERK promotes translocation of NF-KB into the nucleus to control the expression of miR-30c- $2^{*}$ under ER stress. miR-30c-2* in turn negatively regulates the expression of XBP1s mRNA. $\mathbf{b}$ Activated IRE1 and PERK signaling pathways increase the MALAT1 expression. The transcription factor $\mathrm{CHOP}$ transcriptionally regulates expression of Inc-MGC and GOLGA2P10 
tumor cells, which was shown to promote tumor cell progression [73]. Furthermore, restoring the level of miR199a-3p in HCC cells led to G1 phase cell cycle arrest, reduced invasiveness, increased sensitivity to hypoxia, and increased sensitivity to doxorubicin-induced apoptosis through targeting rapamycin (mTOR) [74]. Jiang et al. revealed that increased miR-1281 induced by ER stress promoted apoptosis in osteosarcoma. p53 directly bound to the promoter of miR-1281, contributing to its transcription under ER stress. Luciferase reporter gene assays showed that USP39 was the target of miR-1281 [75].

IRE1 has endoribonuclease (RNase) activity, which can remove a 26 base pair intron from XBP1 mRNA to generate activated XBP1s. XBP1s stimulates the synthesis of multiple UPR target genes [76]. Sustained IRE1 $\alpha$ RNase activation results in rapid degradation of certain miRNAs, including miR-17, miR-34a, miR-96, and miR$125 \mathrm{~b}$, which normally inhibit caspase- 2 mRNA translation, leading to a sharply increasing protein level of this initiator protease in the apoptotic pathway [77]. On the contrary, inhibition of IRE1 $\alpha$ RNase activity through the use of small-molecule inhibitors (2-hydroxy-1-naphthaldehyde, HNA) can increase the expression of many miRNAs in acute myeloid leukemia (AML) cells, including miR-34a. MiR-34a, in turn, enhances the sensitivity of AML cell lines to IRE1 inhibitors [78]. Therefore, inhibiting the IRE1 $\alpha$-driven survival pathway may be a promising application for the treatment of AML.

PERK was previously thought to be a regulator of miRNAs accumulation during ER stress. Indeed, ER stressinduced miRNAs expression partially depends on the PERK-eIF2 $\alpha$-ATF4-CHOP pathway [79-81]. CHOP also regulates miRNAs expression under ER stress in tumor cells. Studies have demonstrated that $\mathrm{CHOP}$ binds to the miR-216b promoter region and regulates miR-216b expression in a Dicer-dependent manner during ER stress. miR-216b directly binds to the $3^{\prime}$ UTR of c-JUN, antagonizes c-JUN accumulation and thereby enhances apoptosis [79, 82]. In addition, PERK could activate NF-kB via phosphorylation of eIF $2 \alpha$, which translocate into the nucleus to activate target genes [83]. For example, NF- $\mathrm{KB}$, as a downstream molecule of PERK, is involved in inducing the regulation of miR-30c-2* expression under ER stress. miR-30c-2* in turn negatively regulates the mRNA expression of XBP1s [80]. Previous studies have demonstrated that PERK signaling induces expression of miR-211, which directly targets the proximal CHOP promoter, where it increases histone methylation and inhibits CHOP expression. In other words, miR-211 is a pro-survival miRNA that regulates $\mathrm{CHOP}$ expression in a PERK-dependent manner [84]. PERKinduced miR-211 inhibition of Bmal1 and Clock in tumor cells is another mechanism that has been recently demonstrated where this pathway inhibits circadian rhythm oscillations and ongoing protein synthesis, thereby promoting tumor progression [81].

\section{ER stress regulates IncRNAs expression}

In response to ER stress, tumor cells inevitably regulate a variety of gene expression levels, including that of long non-coding RNAs. Recently, it has been found that lncRNAs expression can be regulated by ER stress to participate in the regulation of survival and migration of cancer (Table 2, Fig. 2b). Some UPR downstream transcription factors regulate lncRNAs transcription. For instance, the transcription factor CHOP has been reported to be a key transcriptional regulator to control lnc-MGC. Knockdown of CHOP using siRNA significantly suppressed the induction of lnc-MGC [85]. Wu et al. reported that CHOP can directly bind to the promoter of the lncRNA Golgin A2 pseudogene 10 (GOLGA2P10). Aberrant expression of GOLGA2P10 increases the level of the anti-apoptosis gene BCL-xL, which confers cancer cells with resistance to the cytotoxic effects of ER stress and are more likely to survive under harsh conditions [26]. In addition, lncRNAs metastasis-associated lung adenocarcinoma transcript 1 (MALAT1) is upregulated by a pharmacological agent of ER stress induction [86]. Further studies have shown that activated IRE1 and PERK signaling pathways increase the expression of MALAT1, which promote colorectal cancer (CRC) cell migration. Bioinformatic analysis has indicated XBP1 and ATF4 binding sites within the MALAT1 gene promoter region [87]. It has been believed that ER stress-regulated lncRNAs play

Table 2 ER stress-regulated IncRNAs and their potential mechanisms in cancers

\begin{tabular}{|c|c|c|c|c|c|}
\hline LncRNAs & Expression level & Tumor type & UPR-related mechanism & Biological process & References \\
\hline GOLGA2P10 & Upregulated & $\mathrm{HCC}$ & $\begin{array}{l}\text { CHOP can directly bind to the GOL- } \\
\text { GA2P10 promoter }\end{array}$ & $\begin{array}{l}\text { Induces resistance to cytotoxic effect of } \\
\text { ER stress }\end{array}$ & {$[26]$} \\
\hline MALAT1 & Upregulated & Colorectal cancer & $\begin{array}{l}\text { Activated IRE1 and PERK signaling path- } \\
\text { ways increase MALAT1 expression }\end{array}$ & Promotes the migration of $C R C$ cells & {$[87]$} \\
\hline MIAT & Upregulated & Breast cancer & $\begin{array}{l}\text { Overexpression of GRP78 upregulates } \\
\text { the expression of MIAT by increasing } \\
\text { OCT4 in 5-fluorouracil resistant cells }\end{array}$ & Contributes to 5-FU resistance & {$[175]$} \\
\hline
\end{tabular}


critical roles in tumor progression. For instance, ABTB7A acts as an important pro-survival factor in osteosarcoma cells. Under pharmacological ER stress, osteosarcoma cells downregulate ABTB7A expression and promotes apoptosis. Further mechanistic studies revealed that miR663a induced by ER stress directly binds to the $3^{\prime} \mathrm{UTR}$ of ZBTB7A and mediates ER stress-induced ZBTB7A downregulation. Interestingly, ABTB7A transcriptionally inhibited the expression of lncRNA GAS5 by directly binding the promoter of lncRNA GAS5 [88].

\section{NcRNAs regulate UPR in cancer progression MiRNAs regulate UPR in cancer}

MiRNAs directly or indirectly act on UPR pathway molecules to regulate intracellular homeostasis and affect carcinogenic processes, including survival, apoptosis, invasion, metastasis, cancer stem cell characteristics, and the tumor microenvironment (Table 3, Fig. 3).

\section{Survival and apoptosis}

CHOP activation has long been generally considered to be the main pathway for ER stress-related apoptosis [89]. A recent study has shown that the deficiency/ deletion of CHOP in $\mathrm{T}$ cells triggers spontaneous antitumor $\mathrm{CD}^{+} \mathrm{T}$ cell activity and increases the effects of $\mathrm{T}$ cell immunotherapy [90]. Selected miRNAs act indirectly on CHOP to regulate tumor cell apoptosis. Treatment of hematological tumor cells with spatholobus suberectus Dunn (SSD) can upregulate ER stressrelated proteins, including CHOP and p-ATF2, whereas miR-657 is significantly reduced. MiR-657 mimics can attenuate the expression of CHOP, p-ATF2, and PARP cleavage to reverse SSD-induced apoptosis [91]. Similarly, Cnidium officinale Makino (COM) has been known to be an anticancer compound that also downregulates the expression of miR-211 in U937 and U266 cells. The downregulated miR-211 is associated with $\mathrm{CHOP}$ and triggers tumor cell apoptosis [92]. Moreover, the overexpression of miR-34c, a tumor suppressor, significantly increased the levels of eIF $2 \alpha$ and IRE $1 \alpha$ by directly targeting the 3'UTR of HMGB1 and inhibits HMGB1 translation, promoting non-small cell lung cancer (NSCLC) apoptosis [93]. MiRNAs usually target mRNAs to cause translation inhibition and degradation. However, whether those miRNAs directly targeted CHOP mRNA requires further elucidation.

Table 3 MiRNAs directly or indirectly regulate UPR pathway components

\begin{tabular}{|c|c|c|c|c|c|}
\hline Regulators & Effectors & Targets & Cancer type & Biological process & Reference \\
\hline miR-233 & HSP70 & HSPA1A & Osteosarcoma & Regulates apoptosis & {$[25]$} \\
\hline miR-216b & $\mathrm{CHOP}$ & C-JUN & Osteosarcoma & Sensitizes cells to apoptosis & {$[79]$} \\
\hline $\operatorname{miR}-30 c-2^{*}$ & XBP1 & XBP1 & Cervical cancer & $\begin{array}{l}\text { Influences the fate of cells challenged with } \\
\text { ER stress }\end{array}$ & {$[80]$} \\
\hline miR-657 & $\mathrm{CHOP}$ & NA & Hematological cancer & $\begin{array}{l}\text { Attenuates the expression of CHOP, p-ATF2, } \\
\text { and PARP cleavage to reverse SSD-induced } \\
\text { apoptosis }\end{array}$ & {$[91]$} \\
\hline miR-211 & $\mathrm{CHOP}$ & NA & Lymphoma, multiple myeloma & Attenuates COM-induced apoptosis & [92] \\
\hline $\operatorname{miR}-34 c$ & elF2a CHOP IRE1a & HMGB1 & NSCLC & $\begin{array}{l}\text { Inhibits cell proliferation, promotes apoptosis, } \\
\text { and induces ER stress in NSCLC cells }\end{array}$ & {$[93]$} \\
\hline miR-451a & GRP78 PERK elF2a ATF4 CHOP & BAP31 & Colorectal cancer & Inhibits proliferation and increases apoptosis & {$[98]$} \\
\hline miR-410 & CHOP GRP94 GRP78 elF2a & ERLIN2 & Breast cancer & Inhibits cell migration and invasion and EMT & {$[108]$} \\
\hline $\begin{array}{l}\operatorname{miR}-224 \\
\text { miR-520c }\end{array}$ & ATF6a & TUSC3 & NSCLC & $\begin{array}{l}\text { Enhances UPR and ERAD to promote meta- } \\
\text { static potential of }\end{array}$ & {$[109]$} \\
\hline miR-122 & GRP78 CHOP & CDK4 & $\mathrm{HCC}$ & $\begin{array}{l}\text { Regulates anticancer drug-mediated apop- } \\
\text { tosis }\end{array}$ & {$[167]$} \\
\hline miR-146a & $\mathrm{CHOP}$ & $\mathrm{CHOP}$ & Lung cancer & $\begin{array}{l}\text { Reduces the sensitivity of lung cancer cells to } \\
\text { cisplatin }\end{array}$ & {$[171]$} \\
\hline miR-7112-3p & PERK & PERK & Colorectal cancer & $\begin{array}{l}\text { Enhances apoptosis in CX-1 cells treated with } \\
\text { DVDMS-PDT }\end{array}$ & {$[174]$} \\
\hline miR-1202 & GRP78 & Rab1A & Glioma & $\begin{array}{l}\text { Inhibits proliferation and induces ER stress } \\
\text { and apoptosis }\end{array}$ & {$[187]$} \\
\hline miR-15b-5p & GRP78 & Rab1A & $\mathrm{HCC}$ & Induces apoptosis & {$[188]$} \\
\hline miR-1291 & IRE1a & IRE1a & $\mathrm{HCC}$ & Regulates glypican-3 mRNA expression & {$[189]$} \\
\hline $\begin{array}{l}\text { miR-30d miR- } \\
\text { 181a miR- } \\
\text { 199a-5p }\end{array}$ & GRP78 & GRP78 & Prostate cancer & $\begin{array}{l}\text { Suppresses GRP78 levels and GRP78-medi- } \\
\text { ated chemoresistance }\end{array}$ & [190] \\
\hline
\end{tabular}


a $\quad$ b

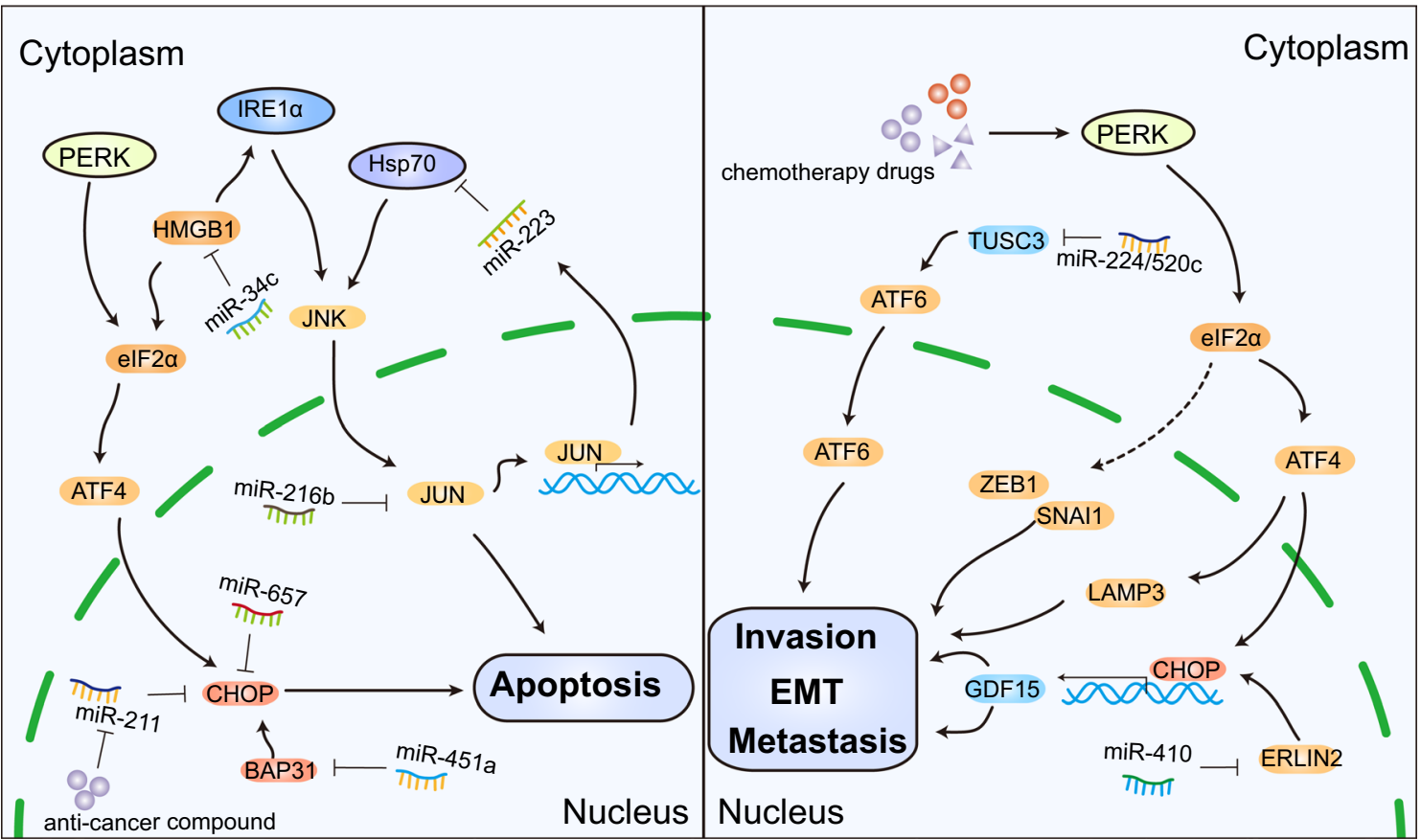

Fig. 3 MiRNAs regulate tumor characteristics including apoptosis, invasion, EMT, and metastasis by regulating the UPR. a MiR-657 mimics can attenuate the CHOP expression to reverse apoptosis. Anticancer compounds downregulate the expression of miR-211 in U937 and U266 cells. The downregulated miR-211 is associated with CHOP and triggers tumor cell apoptosis. MiR-34c overexpression significantly increased the levels of elF2 $a$ and IRE1 $a$ by directly targeting the $3^{\prime} \mathrm{UTR}$ of HMGB1 and inhibiting HMGB1 translation, promoting apoptosis. The expression of miR-216b directly targets c-JUN and inhibition of c-JUN sensitizes cells to apoptosis. MiR-451a increases apoptosis by suppressing BAP31 to induce ER stress. MiR-233 downregulates the heat shock protein 70 (Hsp70) protein levels and downstream JNKJJUN signaling pathways, thereby enhancing apoptosis. JUN can bind to the promoter region of miR-223 to promote its transcription, forming a feedback loop. $\mathbf{b}$ Some chemotherapy drugs activate the PERK pathway by upregulating the expression levels of SNAI1 and ZEB1. LAMP3 is regulated by activation of the PERK/eIF2a/ATF4 arm of the UPR to promote lymph node metastasis. CHOP induced by PERK- elF2a can bind to GDF15 and activate its transcription, regulating EMT and metastasis. MiR-410 directly targets ERLIN2 to up-regulate UPR components to inhibit the migration, invasion, and EMT of breast cancer cells. MiR-224/-520c-dependent TUSC3 deletion enhances NSCLC metastasis via increased ATF6a activity

Under severe and irreparable stress conditions, the IRE1 $\alpha$-ASK1-JNK/c-JUN signaling pathway may trigger apoptosis [33, 94]. JNK downregulates anti-apoptotic proteins, such as BCL-2, BAD, and BAX, and simultaneously activates pro-apoptotic BID, BIM, and Bcl-2-modified factors (BMF) to initiate apoptosis $[95,96]$. However, it should be noted that the UPR-mediated JNK signaling is biphasic. When it is immediately activated in its early stage, it has an anti-apoptotic effect, but in the late stage, it can promote cell death. This opposite effect of JNK on cell viability exists in ER stress [97]. Evidence suggests that ER stress-dependent miR-216b induction occurs via a pathway consisting of PERK, eIF2a, ATF4, and CHOP. The expression of miR-216b directly targets $\mathrm{c}-\mathrm{JUN}$, and inhibition of c-JUN sensitizes cells to apoptosis. CHOPdependent miR-216b transcription downregulates c-JUN expression, thereby amplifying the pro-apoptotic activity of CHOP [79]. Similarly, miR-451a can regulate CRC cell survival by activating ER stress. Elevated miR-451a increases the expression of ER stress-associated proteins, including BIP and PERK/elF2 $\alpha / A T F 4 / C H O P$. Dual-luciferase reporter assays detected that $\mathrm{B}$ cell receptor-associated protein 31 (BAP31) was a direct target of miR-451a. MiR-451a inhibits proliferation and increases apoptosis by suppressing BAP31 to induce ER stress in CRC [98]. In addition, miR-233 downregulates the heat shock protein 70 (Hsp70) protein level and downstream JNK/JUN signaling pathways by binding to the HSPA1A $3^{\prime} \mathrm{UTR}$, thereby regulating osteosarcoma cells apoptosis. JUN is a downstream transcription factor of JNK signaling and can bind to the promoter region of miR-223 to promote its transcription. In short, miR-223, Hsp70, and downstream JNK/JUN form a feedback loop [25] (Fig. 3a).

\section{Invasion and metastasis}

Carcinoma cells reprogram their differentiation status through the epithelial-to-mesenchymal transition (EMT), thereby acquiring the key malignant characteristics of 
invasion and metastasis. Current evidence suggests that UPR signaling promotes tumor progression through activation of the invasion-metastasis cascade, of which EMT plays a vital role [99]. In human tumor tissue, EMT gene expression is closely related to the extracellular matrix (ECM) and PERK-eIF2 $\alpha$ signaling but not to other branches of the UPR [100]. Evidence suggests that some chemotherapy drugs such as cisplatin, cytarabine, doxorubicin, gemcitabine, vinorelbine, etoposide, and pemetrexed activate the PERK pathway and eventually induce EMT by upregulating the expression levels of SNAI1 and ZEB1 [101]. ER stress is often considered a drug-induced side effect caused by these anticancer drugs.

Hypoxia can not only act as a stressor to activate ER stress [102] but also as an inducer of EMT in cancer [103]. Lysosomal-associated membrane protein 3 (LAMP3), a hypoxia-inducible gene, is regulated by activation of the PERK/eIF2a/ATF4 arm of the UPR to promote lymph node metastasis in breast and cervical cancer $[104,105]$. Interestingly, under hypoxia exposure, CHOP induced by PERK-eIF2 $\alpha$ can bind to growth differentiation factor 15 (GDF15) and activate its transcription, regulating EMT and the metastasis of colorectal cancer cells. This indicates that CHOP-activated GDF15 expression is required to maintain CRC cell survival [106]. IRE1 has also been involved in promoting cell survival under hypoxic conditions, and wild-type cells exposed to hypoxia have reduced in vitro survival compared to XBP1-deficient cells [107]. It has been reported that cancer cells undergoing EMT adapt to ER stress by activating the PERK branch of the UPR. Disruption of the PERK pathway significantly increases the sensitivity of cancer cells to ER stressors [100]. MiRNAs regulate ER stress by acting on target genes, which plays an important role in EMT, promoting tumor invasion and metastasis. MiR-410 acts as a tumor suppressor to inhibit cell migration, invasion, and EMT in breast cancer cells. Further studies have shown that miR-410 can enhance the levels of CHOP, GRP94, Bip, and p-PERK. Endoplasmic reticulum lipid raft-associated 2 (ERLIN2) is a direct target of miR-410 [108]. MiR-224/-520c-dependent TUSC3 downregulation enhances the metastasis of NSCLC through increased ATF6 $\alpha$ activity [109] (Fig. 3b).

\section{Tumor microenvironment}

Tumor cells with high metabolism are prone to hypoxia, glucose deficiency, lactic acidosis, oxidative stress, and reduced amino acid supply. All of these changes in the microenvironment contribute to activation of the UPR $[3,110]$. Cancer cells are exposed to ER stress secrete unknown soluble factors, and these mediators can cause macrophages to initiate ER stress accompanied by transcriptional activation and pro-tumor proinflammatory cytokine secretion in a toll like receptor 4 (TLR4)-dependent manner [111]. Similar studies have also demonstrated that cytokines in the tumor microenvironment, such as IL-4, IL-6, and IL-10, can activate the IRE1 $\alpha$-XBP1 branch [37]. Extracellular vesicles, particularly exosomes, as an important component in the tumor microenvironment, can also be used as a medium for transmitting ER stress. A current study has shown that extracellular vesicles derived from AML cells carry BMP2 to transmit ER stress to mesenchymal stem cells (MSCs) and osteoblastic progenitor cells (OPCs) [112]. MiRNAs are one of the most significant components in exosomes, which play an important role in the transmission of information between cells. For example, exosomes secreted by gastric cancer cells transfer miR-15b-3p to recipient gastric cancer cells, promoting the progression of gastric cancer through the dynein light chain Tctex-type 1/ caspase-3/caspase-9 signaling pathway [113]. Transmissible ER stress also impacts the function of immune cells and subsequently promotes tumor survival, progression, and metastasis [111, 114]. ER-stressed HCC releases exosomes trafficking miR-23a-3p to upregulate PD-L1 expression in macrophages and inhibit $\mathrm{T}$ cell function, which promotes tumor cells to escape immune surveillance [115]. Similarly, ER stress contributes to exosome secretion and enhanced exosomal miR-27a-3p expression in breast cancer. Exosomes carrying miR-27a-3p target macrophages in the microenvironment. MiR-27a-3p could target MAGI2 and negatively regulate MAGI2 expression, while downregulation of MAGI2 upregulated PD-L1 expression via the PTEN/PI3K signaling pathway [66]. In general, in the tumor microenvironment, ERstressed tumor cells transmit information to other cells, such as immune cells, through exosomes carrying cargo (Fig. 4).

\section{Cancer stem cell characteristics}

Tumor stem cells can remain dormant for a long period of time and are insensitive to a variety of unfavorable risk factors, which play critical roles in tumor initiation, progression, recurrence, and metastasis [116, 117]. It has been shown that tumor stem cells exhibit enhancement for ER stress resistance, which contributes to tumor growth, angiogenesis, and resistance to chemotherapy $[118,119]$. In ER stress-resistant melanoma, the number of cancer stem cells is significantly increased. The underlying mechanism involves Hoxb9 binding to the miR-765 promoter and promoting its transcription. The highly expressed miR-765 targets Forkhead box A2 (Foxa2), resulting in a decrease in Foxa2 expression, and enhancement of tumor stem cells renewal, and apoptosis inhibition [120]. Further research is needed to eliminate tumor stem cells by regulating ER stress. 


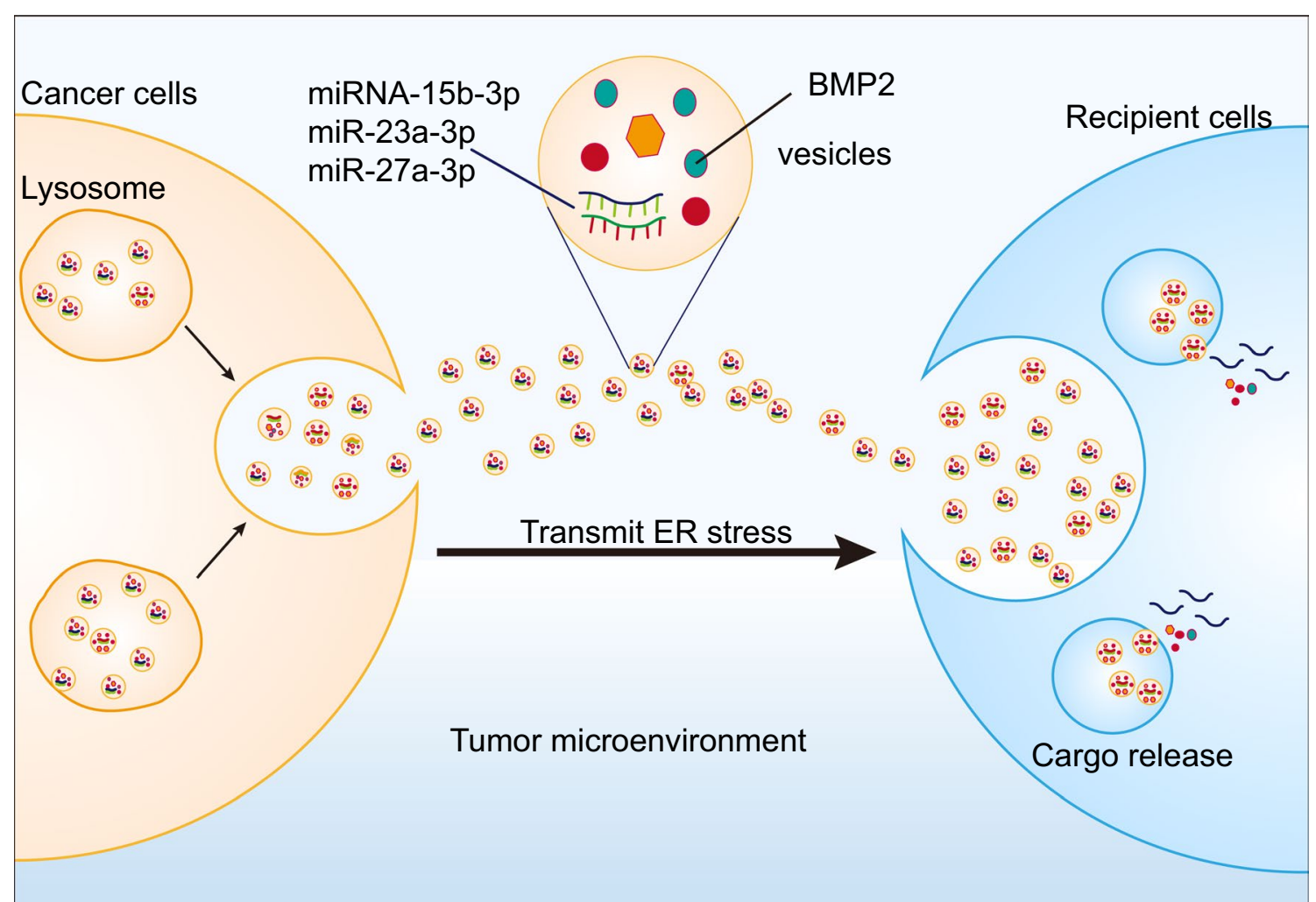

Fig. 4 ER stress is transmitted by extracellular vesicles harboring miRNAs in the tumor microenvironment. Extracellular vesicles derived from tumor cells carry miRNAs and/or proteins that transmit ER stress from tumor cells to recipient cells, thus affecting the function of recipient cells

\section{LncRNAs regulate the UPR in cancer progression}

LncRNAs exert their molecular functions through RNA-protein, RNA-RNA, or RNA-DNA interactions. Abnormal lncRNAs expression has been implicated in cancer progression via their regulation of the UPR (Table 4, Fig. 5).

\section{Apoptosis}

Many tumor-related lncRNAs can regulate the proliferation and apoptosis of tumor cells by activating the UPR [121-123]. Recent studies have shown that ectopic expression of MEG3 increases the expression of ER stress-related proteins, including GRP78, IRE1, PERK, ATF6, and CHOP and is accompanied by NF- $\mathrm{kB}$ translocation from the cytoplasm to the nucleus. Consequently, MEG3 may inhibit growth and induce the apoptosis of cancer cells [121-123]. It has been revealed that MEG3 competitively combines with miR-7-5p to upregulate the STC1 level, thus accelerating ER stress-mediated apoptosis in cervical carcinoma, which has been termed a competing endogenous RNA (ceRNA) model [124]. Moreover, MEG3 was downregulated in human CRC. Restoring MEG3 in these cells promote the expression of ER stress-related proteins, including GRP78, ATF6, and CHOP through the formation of a sponge with miR-103a-3p [125]. Another study has also shown that MEG3 remarkably upregulates the ER stress-related protein GRP78 and activates NF- $\mathrm{kB}$ signaling to affect the apoptosis of gallbladder cancer cells [126]. In addition, the lncRNA CASC2 was negatively correlated with the malignancy of NSCLC cells. Overexpression of CASC2 increases the stability of PERK mRNA, which triggers the PERK/eIF2 $\alpha / C H O P$ pathway and promotes radiationinduced apoptosis of NSCLC cells [127]. FOXD3-AS1 has been shown to be upregulated in nasopharyngeal carcinoma tissues and cells. Further research has revealed that FOXD3-AS1 could competitively bind to let-7e-5p to regulate RCN1. Silencing FOXD3-AS1 or upregulating let-7e-5p increases the expression profiles of GRP78, CHOP, ATF4, caspase-12, and caspase- 9 , consequently promoting ER stress-induced apoptosis in nasopharyngeal carcinoma [128]. Furthermore, lincRNA-p21 acts as a tumor suppressor and is downregulated in numerous tumors. Overexpression of lincRNA-p21 significantly inhibits cell proliferation capacity, induces G1 arrest and apoptosis, and increases radiosensitivity of hepatocellular carcinoma cells $[129,130]$. LincRNA-p21 is also involved in regulating drug resistance. Sorafenib, a 
Table 4 LncRNAs regulate UPR pathway components

\begin{tabular}{|c|c|c|c|c|c|}
\hline LncRNAs & Expression level & Tumor type & UPR-related mechanism & Biological process & References \\
\hline \multirow[t]{5}{*}{ MEG3 } & & Breast cancer & $\begin{array}{l}\text { Increases ER stress-related proteins } \\
\text { (GRP78, IRE1, PERK, ATF6, and CHOP) } \\
\text { and NF-KB }\end{array}$ & Inhibits growth, induces apoptosis & [121] \\
\hline & Downregulated & ESCC & $\begin{array}{l}\text { Increases ER stress-related proteins } \\
\text { (GRP78, IRE1, PERK, ATF6, and CHOP), } \\
\text { caspase-9, and cleaved caspase-3 }\end{array}$ & Inhibits cell growth, induces apoptosis & [122] \\
\hline & Downregulated & $\mathrm{HCC}$ & $\begin{array}{l}\text { Increases ER stress-related proteins } \\
\text { (GRP78, IRE1, PERK, ATF6, and CHOP) }\end{array}$ & $\begin{array}{l}\text { Inhibits proliferation, induces apop- } \\
\text { tosis }\end{array}$ & [123] \\
\hline & Downregulated & Cervical carcinoma & $\begin{array}{l}\text { Competing endogenous RNA of } \\
\text { miR-7-5p }\end{array}$ & $\begin{array}{l}\text { Accelerate ER stress-mediated } \\
\text { apoptosis }\end{array}$ & [124] \\
\hline & Downregulated & Colorectal carcinoma & $\begin{array}{l}\text { Increases ER stress-related proteins } \\
\text { (GRP78, ATF6, and CHOP) }\end{array}$ & Suppresses proliferation and invasion & [125] \\
\hline CASC2 & Downregulated & NSCLC & Increases PERK mRNA stability & Promotes radiation-induced apoptosis & [127] \\
\hline FOXD3-AS1 & Upregulated & NPC & $\begin{array}{l}\text { Silencing FOXD3-AS1 promotes ER } \\
\text { stress-induced apoptosis by com- } \\
\text { petitively binding to let-7e-5p }\end{array}$ & $\begin{array}{l}\text { Silencing of FOXD3-AS1 induces } \\
\text { apoptosis }\end{array}$ & {$[128]$} \\
\hline LincRNA-p21 & Downregulated & $\mathrm{HCC}$ & $\begin{array}{l}\text { Induces expression of IRE1, CHOP, and } \\
\text { GRP78 and upregulates the phos- } \\
\text { phorylation level of PERK }\end{array}$ & $\begin{array}{l}\text { Contributes to sorafenib-induced ER } \\
\text { stress and apoptosis }\end{array}$ & [132] \\
\hline NORAD & Upregulated & Melanoma & $\begin{array}{l}\text { Knockdown of NORAD can inhibit } \\
\text { UPR-related genes including GRP78, } \\
\text { CHOP, and elF2a }\end{array}$ & Promotes invasion and migration & [136] \\
\hline NEAT1 & Upregulated & Multiple myeloma & $\begin{array}{l}\text { Promotes expression of UPR-related } \\
\text { proteins CHOP, XBP-1, and IRE1 }\end{array}$ & $\begin{array}{l}\text { Promotes proliferation, migration, and } \\
\text { invasion }\end{array}$ & [141] \\
\hline LUCRC & Upregulated & Colorectal cancer & Induces the expression of GRP78 & $\begin{array}{l}\text { Promotes proliferation, migration, and } \\
\text { invasion }\end{array}$ & [142] \\
\hline OR3A4 & Upregulated & Osteosarcoma & $\begin{array}{l}\text { Knockdown of OR3A4 inhibits the } \\
\text { expression of G6PD, blocking the } \\
\text { pentose phosphate pathway and } \\
\text { resulting in ER-stress }\end{array}$ & $\begin{array}{l}\text { Promotes proliferation, colony forma- } \\
\text { tion }\end{array}$ & {$[145]$} \\
\hline
\end{tabular}

ESCC, esophageal squamous cell carcinoma; HCC, hepatocellular carcinoma; NSCLC, non-small cell lung cancer; NPC, nasopharyngeal carcinoma

small molecule antitumor drug, could induce the apoptosis of hepatocellular carcinoma cells by inducing ER stress [131]. Interestingly, sorafenib also could induce the expression of lincRNA-p21. Ectopic expression of lincRNA-p21 activated ER stress by inducing the expression of IRE1, CHOP, and GRP78 and up-regulating the phosphorylation level of PERK. Further research found that lincRNA-p21 induced-ER stress-mediated apoptosis is mainly mediated through reactive oxygen species (ROS) in hepatocellular carcinoma cells [132]. Collectively, lincRNA-p21 indirectly regulating ER stress has been demonstrated. However, how lincRNA-p21 activates ER stress remains to be further explored (Fig. 5a).

\section{Invasion and metastasis}

Invasion and metastasis are characteristics of malignant tumors and are leading causes of mortality. LncRNAs can also regulate these complex processes. Non-coding RNA activated by DNA damage (NORAD) has been found to be upregulated in numerous cancer tissues and involved in many biological processes of tumors, including migration and invasion [133-135]. In malignant melanoma,
NORAD may act as a sponge for miR-205 and reduce the transcriptional repression of the miR-205 target gene EGLN2, a key regulator of ER stress. NORAD silencing can inhibit UPR-related gene expression including that of GRP78, CHOP, and eIF2 $\alpha$. Downregulation of NORAD also restrained malignant melanoma cell migration and invasion. However, whether NORAD-induced ER stress promotes the invasion and metastasis of melanoma cells needs to be further studied [136]. In addition, IncRNA nuclear-enriched abundant transcript 1 (NEAT1) is newly discovered and has been localized in cell nuclear paraspeckles. Increasing evidence has revealed that NEAT1 is upregulated in multiple cancers and facilitates cell invasion and migration by being a sponge for miRNAs [137-140]. Recently, NEAT1 has been proven to be highly expressed in multiple myeloma, and knockdown of NEAT1 inhibited the invasion and metastasis of myeloma cells. Overexpression of NEAT1 promotes the expression of UPR-related proteins CHOP, XBP1 , and IRE1, while resveratrol attenuates the effects of NEAT1 on inducing ER stress [141]. Further understanding of the regulation of NEAT1 and UPR by resveratrol 


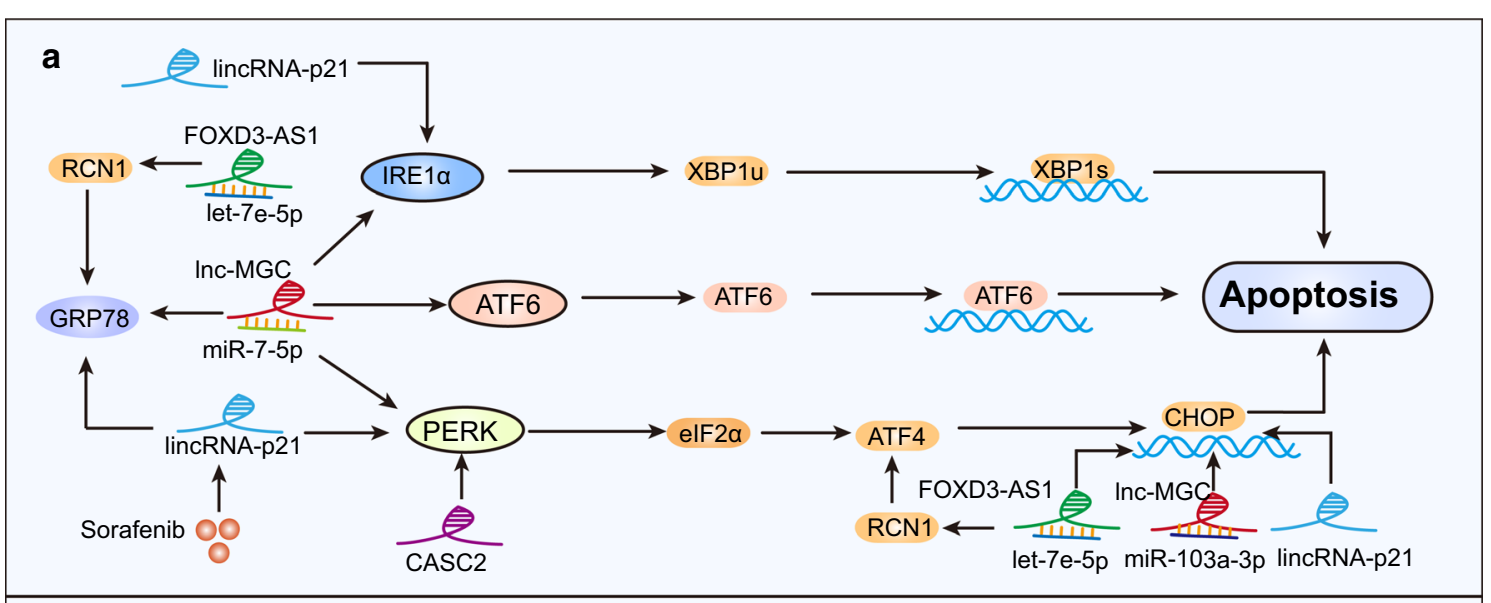

b

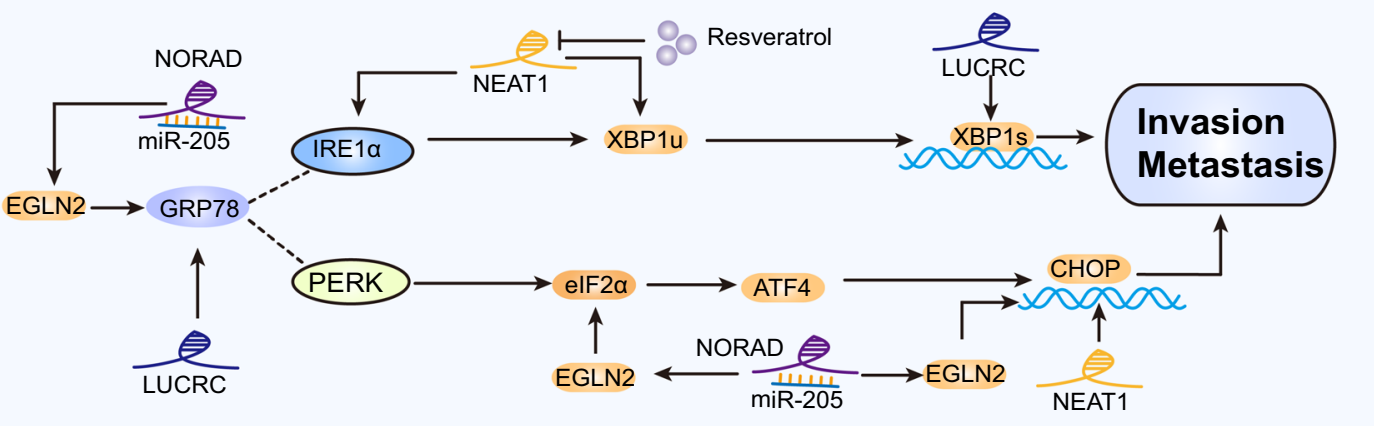

C

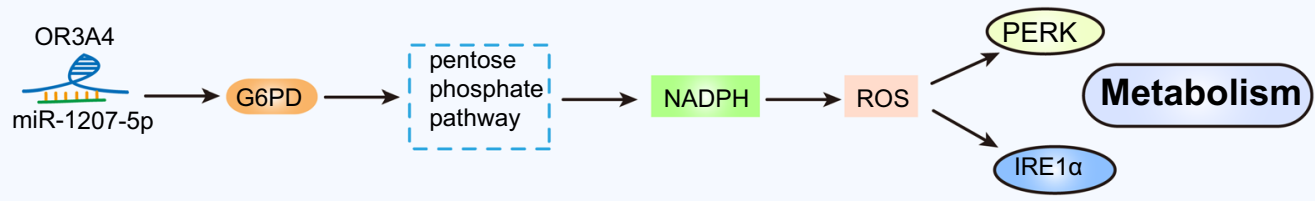

Fig. 5 LncRNAs regulate the tumor characteristics apoptosis (a), invasion and metastasis (b), and metabolism (c) by regulating the UPR. a FOXD3-AS1 could competitively bind to let-7e-5p to regulate RCN1. Silencing FOXD3-AS1 or upregulating let-7e-5p increased the expression profiles of GRP78, CHOP, and ATF4, consequently promoting ER stress-induced apoptosis. MEG3 increased the expression of ER stress-related proteins, including GRP78, IRE1, PERK, ATF6, and CHOP, consequently inhibiting growth and induce the apoptosis of cancer cells. In addition, MEG3 competitively combines with miR-7-5p or miR-103a-3p to promote ER stress-mediated apoptosis. Ectopic expression of lincRNA-p21 activates ER stress by inducing the expression of IRE1, CHOP, and GRP78 and upregulating the PERK phosphorylation level. Sorafenib also could increase the expression of lincRNA-p21 to induce ER stress-mediated apoptosis. Overexpression of CASC2 increases the stability of PERK mRNA, which triggers the PERK/eIF2a/CHOP pathway and promotes radiation-induced apoptosis. b NORAD may act as a sponge for miR-205 and reduce the transcriptional repression of the miR-205 target gene EGLN2. NORAD silencing can inhibit UPR-related gene expression including that of GRP78, CHOP, and elF2a. Downregulation of NORAD also restrained malignant melanoma cell migration and invasion. Overexpression of NEAT1 promote expression of the UPR-related proteins IRE1, XBP-1, and CHOP. Resveratrol attenuates the effects of NEAT1 on inducing ER stress. LUCRC can regulate Bip expression and induce the splicing of XBP1 from XBP1 $\mathrm{u}$ (unspliced) to XBP1s (spliced), resulting in activation of UPR to promote tumor progression. c OR3A4 functions as a sponge for miR-1207-5p, modulating the target gene glucose-6-phosphate dehydrogenase (G6PD). Knockdown of OR3A4 inhibits the expression of G6PD, blocks the pentose phosphate pathway, and significantly reduces the level of nicotinamide adenine dinucleotide phosphate (NADPH). This abnormal metabolic pathway upregulates the redox state content, which increases the expression of PERK and IRE1 in osteosarcoma cells

may provide a therapeutic strategy for cancer treatment. Another lncRNA, which has only been reported in colorectal cancer, is lncRNA Upregulated in Colorectal Cancer (LUCRC). The expression of LUCRC is increased in
CRC tumor tissue and blood samples, and it is involved in functions such as tumorigenesis in vivo and CRC cell proliferation, migration, and invasion in vitro. Further study demonstrated that LUCRC can regulate the 
expression of the protein folding chaperone Bip and induce the splicing of XBP1 from XBP1u (unspliced) to XBP1s (spliced), resulting in activation of UPR to promote tumor progression [142] (Fig. 5b).

\section{Tumor metabolism}

The reprogramming of metabolism is a critical characteristic that supports the rapid proliferation of cancer cells. LncRNAs mediate glycolysis by regulating key enzymes in the pathway [143-145]. The lncRNA olfactory receptor family 3 subfamily A member 4 (OR3A4) is highly expressed in osteosarcoma and inversely related to the prognosis of patients. OR3A4 functions as a sponge for the miR-1207-5p modulated target gene Glucose-6-phosphate dehydrogenase (G6PD), an enzyme that catalyze the pentose phosphate pathway. Knockdown of OR3A4 increased the expression of miR-1207-5p and inhibited the expression of G6PD, blocking the pentose phosphate pathway and significantly reducing the level of nicotinamide adenine dinucleotide phosphate (NADPH). This abnormal metabolic pathway upregulated the redox state content, which increased the expression of PERK and IRE1 in osteosarcoma cells. The deletion of OR3A4 reduces NADPH production, which may lead to ROS accumulation and aggravate ER stress-induced apoptosis [145] (Fig. 5c).

\section{CircRNAs regulate the UPR in cancer}

As ncRNAs member, circRNAs have been reported to be expressed in almost all types of cells and possibly dysregulated in cancer [146]. CircRNAs are involved in tumor development and are becoming novel biomarkers for diagnosis and prognosis [147]. Recently, several studies have demonstrated that circRNAs could modulate cell survival through the UPR pathway. Circ_002117 was downregulated in gastric cancer compared with adjacent non-cancer tissues. The expression of circ_002117 was negatively correlated with the degree of malignant gastric cancer and positively correlated with the overall survival rate of patients. Augmented circ_002117 expression induced ER stress by upregulating the UPR pathway components GRP78, IRE1, eIF2 $\alpha$, and CHOP, subsequently resulting in apoptosis in gastric cancer cells. The underlying mechanism involves circ_002117 forming a sponge with miR-370, upregulating the HERPUD1 level, and facilitating ER stress-induced apoptosis [148]. CircCDR1as is highly expressed in OSCCs. Overexpression of circCDR1as induced ER stress by upregulating eIF2 $\alpha$ under normal oxygen and hypoxia conditions, increasing OSCC cell viability [149]. Another study reported that circRNA_101036 was downregulated as a tumor suppressor gene in OSCC cell lines. Overexpression of circRNA_101036 induced the UPR pro-apoptosis pathway by increasing the levels of CHOP protein and ROS, which induces apoptosis [150]. Nevertheless, further investigations are still needed to elucidate the full picture of regulation of ER stress by circRNAs in cancer (Table 5, Fig. 6).

\section{Therapeutic strategies based on ncRNAs and the UPR in cancer}

Chemotherapy usually fails because tumor cells acquire multidrug resistance, which is the result of multiple factors, including ER stress tolerance (ERST). Tunicamycininduced ERST has been reported to be more resistant to cisplatin in lung cancer cells [151]. Some antitumor drugs are capable of stimulating GRP78 expression, which in turn induces cell resistance [152-154]. PERK activation can cause cell cycle arrest by specifically inhibiting the synthesis of certain cell cycle regulators. Cancer cells enter into quiescence, which is termed cancer cell dormancy $[155,156]$. Dormant tumor cells are usually able to escape the toxic effects of chemotherapeutic drugs and are thought to be the cause of primary tumor progression and metastatic recurrence [157]. Previous studies have found that dormant tumor cells can upregulate all three major transducers of the UPR, IRE1 $\alpha$, PERK, and ATF6 [67, 158].Moreover, GRP78 has previously been shown downstream of activated p38 and appears to play an important role in inducing drug resistance, which is involved in the maintenance of chemical resistance and stem cell populations in pancreatic cancer $[152,158$, 159]. However, bortezomib-resistant myeloma cells did not upregulate GRP78. Instead, the low expression level of XBP1s and TP53 abnormalities were associated with bortezomib resistance [160]. In addition, ER stress has also been shown to be related to resistance to tyrosine kinase inhibitors by upregulating key survival signals, such as Bcl-xL [161]. Overall, UPR activation has been

Table 5 CircRNAs regulate UPR pathway components

\begin{tabular}{|c|c|c|c|c|c|}
\hline CircRNAs & Expression level & Tumor type & UPR-related Mechanism & Biological process & References \\
\hline Circ_002117 & Downregulated & Gastric cancer & $\begin{array}{l}\text { Increases expression of GRP78, IRE1, } \\
\text { elF2a, and CHOP }\end{array}$ & Promotes apoptosis & [148] \\
\hline CircCDR1 & Upregulated & OscC & Increases elF2a expression & Inhibits apoptosis & {$[149]$} \\
\hline CircRNA_101036 & Downregulated & OscC & Increases CHOP and ROS levels & Induces cell apoptosis & [150] \\
\hline
\end{tabular}




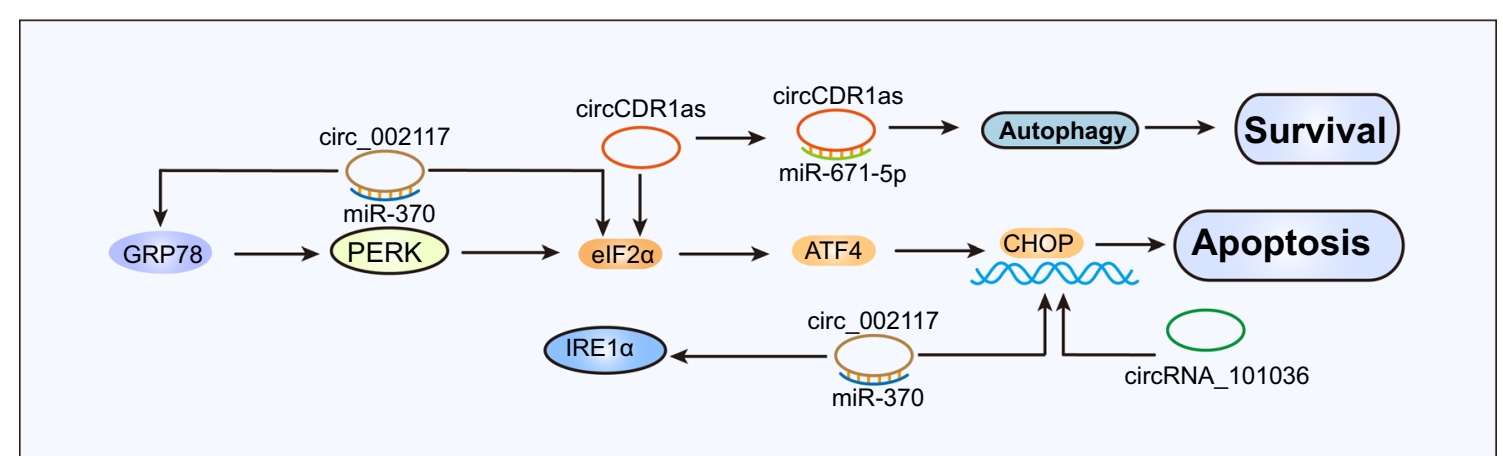

Fig. 6 CircRNAs mediate tumor survival and apoptosis by UPR. Circ_002117 induced ER stress by upregulating GRP78, IRE1, elF2a, and CHOP, subsequently resulting in the apoptosis of gastric cancer cells. CircCDR1as induces ER stress by upregulating elF2a under hypoxia conditions, increasing OSCC cell survival. Moreover, circCDR1as promoted hypoxia-induced autophagy in OSCC cells by sponging miR-671-5p. CircRNA_101036 induced the UPR pro-apoptosis pathway by increasing CHOP protein, which induces apoptosis

shown to mediate chemoresistance. Therefore, small molecule inhibitors targeting UPR components are promising candidates for overcoming drug resistance.

A growing number of studies have proven that miRNAs can act as tumor promoters or suppressors, and their dysregulation promotes tumor metastasis and therapeutic resistance by facilitating the activation of oncogenic signaling pathways [162-164]. For instance, miR-410 as a carcinogenic miRNA contributes to tumorigenesis and increases cell resistance to cisplatin in lung cell lines [165]. In contrast, miR-128 plays a role as a tumor suppressor that inhibits cancer stem cell self-renewal and increases A549 cell sensitivity to paclitaxel [166]. MiRNAs can also be dedicated to the modulation of UPR signaling pathways to regulate the therapeutic sensitivity of tumor cells. MiR-122 exhibited an inhibitory effect on the expression of a chaperone gene, and its overexpression leads to repression of the UPR pathway in HCC. Inhibition of miR-122 upregulates its target gene cyclindependent kinase 4 (CDK4) to enhance the stability of the $26 \mathrm{~S}$ proteasome non-ATPase regulatory subunit 10 (PSMD10). This process activates the UPR to reduce the tumor cell apoptosis mediated by antitumor drugs [167].

$\mathrm{CHOP}$ is an important transcription factor involved in regulating apoptosis and drug sensitivity [168-170]. Studies have shown that the levels of CHOP mRNA and its protein level were significantly lower in lung cancer tissues compared with noncancerous tissues. CHOP downregulation predicted poor overall survival [171]. Furthermore, CHOP modulated the sensitivity of lung cancer cells to cisplatin through regulation of autophagy [171, 172]. MiR-146a directly targets the CHOP $3^{\prime} U T R$ and downregulates $\mathrm{CHOP}$ expression, thus resulting in reduced sensitivity of lung cancer cells to cisplatin. MiR146a may be a potential therapeutic target for resistant lung cancer [171]. Similarly, miR-1271 also directly acts on CHOP mRNA, and consequently promotes letrozoleresistance in breast cancer [173]. Other studies have demonstrated that miR-7112-3p is highly expressed in colorectal cancer tissues. However, sinoporphyrin sodium-induced photodynamic therapy (DVDMS-PDT) can downregulate miR-7112-3p in CX-1 cells, which directly acts on PERK and further regulates the PERKATF4-CHOP-Caspase3/8 signaling pathway, increasing DVDMS-PDT-induced cancer cell apoptosis [174].

GRP78 is highly expressed in 5-fluorouracil resistant cells, which can upregulate the expression of IncRNA myocardial infarction associated transcript (MIAT) by increasing OCT4. Inhibitors of GRP78 or MIAT can alleviate the drug resistance of tumor cells to 5 -fluorouracil [175]. The potential role of UPR in regulating the transcription and function of IncRNAs was suggested. However, this requires further investigation to validate the mechanism of direct regulation.

\section{Conclusive remarks}

Most of the existing evidence indicates that tumor cells initiate the UPR in response to major intrinsic changes and adverse environmental challenges where the UPR operates as a pro-oncogenic mechanism that drives several aspects of cancer development. Therefore, UPR modulators may be used as a biomarker of prognosis and a target of drug therapy. For instance, the expression level of XBP1s is significantly higher in numerous solid tumors, and its increased expression is associated with more malignant phenotypes and poor survival [42, 44, 176]. The overexpression of BiP is also associated with poor prognosis and weak response to treatment in clinical trials $[176,177]$. Because the UPR can trigger pro-survival and pro-apoptotic signals, both inducers and inhibitors targeting UPR molecules can be used as therapeutic agents for tumors, including inhibitors of 
PERK (GSK2606414 and GSK2656157) [178, 179], ATF6 (16F16) [180], and IRE1 $\alpha$ (MKC-3946, STF-083010) [181, 182], and a CHOP inducer (DK143) [183]. However, in certain circumstances, UPR downstream components have been shown to not only regulate ER stress-induced apoptosis, but also promote the growth of tumors. Thus, therapies targeting UPR components that promote cell death or survival require further detailed validation.

Under ER stress, tumor cells undergo a series of biological changes to adapt to growth, including ncRNA expression regulation. Conversely, ncRNAs also regulate UPR downstream target gene expression. UPR-related genes could be upstream regulators or downstream effectors of ncRNAs, forming an interaction network that jointly regulates the hallmarks of cancer. In this review, we systematically discussed mutual regulation of ER stress and ncRNAs (miRNAs, lncRNAs, and circRNAs) in the process of tumorigenesis and development. It is worth further exploring how the UPR is involved in communication and interaction between tumors and stromal cells and the regulation of angiogenesis and the immune response in the tumor microenvironment. Tumor cells releasing exosomes carrying miRNAs may play an important role in cell-cell functional interplay. Transmissible ER stress may be used as a way for cells to interact with each other in the tumor microenvironment. Extracellular vesicles serve as an interactive medium, containing proteins and ncRNAs, and should be further investigated. Over the years, there has been extensive evidence to support that ncRNAs can be selected as therapeutic targets, particularly in the field of oncology. Consequently, treatment targeting the IncRNA-miRNA-UPR pathway is an important strategy for cancer therapy, and the mechanism of action for many ncRNAs is consolidated in this framework. Therefore, significant improvements of cancer treatment are expected through targeting ncRNA and ER stress in the near future.

In conclusion, ncRNAs have been identified as major participants in complex UPR regulatory networks and have been found to be involved in many aspects of human malignancies. Additionally, the UPR also regulates ncRNA levels in tumor. This dual regulation of ER stress and ncRNAs provides further insights into the understanding of tumorigenesis and therapeutic strategies.

\footnotetext{
Abbreviations

ER: Endoplasmic reticulum; ER stress: Endoplasmic reticulum stress; UPR: Unfolded protein responses; NcRNAs: Non-coding RNAs; ENCODE: Encyclopedia of DNA elements; MiRNAs: MicroRNAs; LncRNAs: Long non-coding RNAs; CircRNAs: Circular RNAs; UTR: Untranslated region; ERAD: Endoplasmic reticulum-associated degradation; OSCC: Oral squamous cell carcinoma; HCC: Hepatocellular carcinoma; TNBC: Triple-negative breast cancer; ERSE: Element or ER stress response element; AML: Acute myeloid leukemia; CRC: Colorectal cancer; SSD: Spatholobus suberectus Dunn; COM: Cnidium officinale Makino;
} NSCLC: Non-small cell lung cancer; EMT: Epithelial-to-mesenchymal transition;
ECM: Extracellular matrix; MSCs: Mesenchymal stem cells; OPCs: Osteoblastic progenitor cells; ROS: Reactive oxygen species; NADPH: Nicotinamide adenine dinucleotide phosphate; ERST: ER stress tolerance; DVDMS-PDT: Sinoporphyrin sodium-induced photodynamic therapy.

\section{Acknowledgements}

We were very grateful to Professor Yangqiu Li for critically reading the manuscript.

\section{Authors' contributions}

TMZ wrote the manuscript. JD and $\mathrm{HZ}$ reviewed and revised the manuscript. All authors read and approved the final manuscript.

\section{Funding}

The project is supported by the National Natural Science Foundation of China (No. 81770184 and 81970143).

\section{Availability of data and materials}

The material supporting the conclusion of this review has been included within the article.

\section{Ethics approval and consent to participate}

Not applicable.

\section{Consent for publication}

Not applicable.

\section{Competing interests}

The authors declare that they have no competing interests.

Received: 24 October 2020 Accepted: 17 November 2020

Published online: 02 December 2020

$$
\begin{aligned}
& \text { References } \\
& \text { 1. Araki K, Nagata K. Protein folding and quality control in the ER. Cold } \\
& \text { Spring Harb Perspect Biol. 2012;4(8):a015438. } \\
& \text { 2. Tabas I, Ron D. Integrating the mechanisms of apoptosis induced by } \\
& \text { endoplasmic reticulum stress. Nat Cell Biol. 2011;13(3):184-90. } \\
& \text { 3. Wang M, Kaufman RJ. The impact of the endoplasmic reticulum } \\
& \text { protein-folding environment on cancer development. Nat Rev Cancer. } \\
& \text { 2014;14(9):581-97. } \\
& \text { 4. Tameire F, Verginadis II, Koumenis C. Cell intrinsic and extrinsic activa- } \\
& \text { tors of the unfolded protein response in cancer: Mechanisms and } \\
& \text { targets for therapy. Semin Cancer Biol. 2015;33:3-15. } \\
& \text { 5. Bertolotti A, Zhang Y, Hendershot LM, Harding HP, Ron D. Dynamic } \\
& \text { interaction of BiP and ER stress transducers in the unfolded-protein } \\
& \text { response. Nat Cell Biol. 2000;2(6):326-32. } \\
& \text { 6. Shen J, Chen X, Hendershot L, Prywes R. ER stress regulation of ATF6 } \\
& \text { localization by dissociation of BiP/GRP78 binding and unmasking of } \\
& \text { Golgi localization signals. Dev Cell. 2002;3(1):99-111. } \\
& \text { 7. Djebali S, Davis CA, Merkel A, Dobin A, Lassmann T, Mortazavi } \\
& \text { A, et al. Landscape of transcription in human cells. Nature. } \\
& \text { 2012;489(7414):101-8. } \\
& \text { 8. The ENCODE Project Consortium. An integrated encyclopedia of DNA } \\
& \text { elements in the human genome. Nature. 2012;489(7414):57-74. } \\
& \text { 9. Lee RC, Feinbaum RL, Ambros V. The C. elegans heterochronic gene lin-4 } \\
& \text { encodes small RNAs with antisense complementarity to lin-14. Cell. } \\
& \text { 1993;75(5):843-54. } \\
& \text { 10. Liu Y, Cheng Z, Pang Y, Cui L, Qian T, Quan L, et al. Role of microRNAs, } \\
& \text { circRNAs and long noncoding RNAs in acute myeloid leukemia. J } \\
& \text { Hematol Oncol. 2019;12(1):51. } \\
& \text { 11. Memczak S, Jens M, Elefsinioti A, Torti F, Krueger J, Rybak A, et al. Circular } \\
& \text { RNAs are a large class of animal RNAs with regulatory potency. Nature. } \\
& \text { 2013;495(7441):333-8. } \\
& \text { Rinn JL, Chang HY. Genome regulation by long noncoding RNAs. Annu } \\
& \text { 13, Co17;16(3):167-79. }
\end{aligned}
$$


14. Dong Y, He D, Peng Z, Peng W, Shi W, Wang J, et al. Circular RNAs in cancer: an emerging key player. J Hematol Oncol. 2017;10(1):2.

15. Smolle MA, Calin HN, Pichler M, Calin GA. Noncoding RNAs and immune checkpoints-clinical implications as cancer therapeutics. Febs j. 2017;284(13):1952-66.

16. Wang WT, Han C, Sun YM, Chen TQ, Chen YQ. Noncoding RNAs in cancer therapy resistance and targeted drug development. J Hematol Oncol. 2019;12(1):55.

17. Bracken CP, Scott HS, Goodall GJ. A network-biology perspective of microRNA function and dysfunction in cancer. Nat Rev Genet. 2016;17(12):719-32.

18. Slack FJ, Chinnaiyan AM. The role of non-coding RNAs in oncology. Cell. 2019;179(5):1033-55.

19. Amelio I, Bernassola F, Candi E. Emerging roles of long non-coding RNAs in breast cancer biology and management. Semin Cancer Biol. 2020. https://doi.org/10.1016/j.semcancer.2020.06.019.

20. Fehlmann T, Kahraman M, Ludwig N, Backes C, Galata V, Keller V, et al. Evaluating the use of circulating microRNA profiles for lung cancer detection in symptomatic patients. JAMA Oncol. 2020;6(5):714-23.

21. Yu AM, Choi YH, Tu MJ. RNA Drugs and RNA targets for small molecules: principles, progress, and challenges. Pharmacol Rev. 2020;72(4):862-98.

22. Li J, Huang C, Zou Y, Ye J, Yu J, Gui Y. CircTLK1 promotes the proliferation and metastasis of renal cell carcinoma by sponging miR-136-5p. Mol Cancer. 2020;19(1):103

23. Hong $X$, Liu N, Liang Y, He Q, Yang X, Lei Y, et al. Circular RNA CRIM1 functions as a ceRNA to promote nasopharyngeal carcinoma metastasis and docetaxel chemoresistance through upregulating FOXQ1. Mol Cancer. 2020;19(1):33.

24. Xiu B, Chi Y, Liu L, Chi W, Zhang Q, Chen J, et al. LINC02273 drives breast cancer metastasis by epigenetically increasing AGR2 transcription. Mol Cancer. 2019;18(1):187.

25. Tang Q, Yuan Q, Li H, Wang W, Xie G, Zhu K, et al. miR-223/Hsp70/ JNK/JUN/miR-223 feedback loop modulates the chemoresistance of osteosarcoma to cisplatin. Biochem Biophys Res Commun. 2018;497(3):827-34.

26. Wu MZ, Fu T, Chen JX, Lin YY, Yang JE, Zhuang SM. LnCRNA GOLGA2P10 is induced by PERK/ATF4/CHOP signaling and protects tumor cells from ER stress-induced apoptosis by regulating $\mathrm{BCl}-2$ family members. Cell Death Dis. 2020;11(4):276.

27. Wang WA, Groenendyk J, Michalak M. Endoplasmic reticulum stress associated responses in cancer. Biochim Biophys Acta. 2014;1843(10):2143-9.

28. Oakes SA. Endoplasmic reticulum stress signaling in cancer cells. Am J Pathol. 2020;190(5):934-46.

29. Moenner M, Pluquet O, Bouchecareilh M, Chevet E. Integrated endoplasmic reticulum stress responses in cancer. Cancer Res. 2007;67(22):10631-4.

30. Hollien J, Weissman JS. Decay of endoplasmic reticulum-localized mRNAs during the unfolded protein response. Science. 2006;313(5783):104-7.

31. Schroder M, Kaufman RJ. The mammalian unfolded protein response. Annu Rev Biochem. 2005;74:739-89.

32. Nishitoh H, Matsuzawa A, Tobiume K, Saegusa K, Takeda K, Inoue $K$, et al. ASK1 is essential for endoplasmic reticulum stress-induced neuronal cell death triggered by expanded polyglutamine repeats. Genes Dev. 2002;16(11):1345-55.

33. Urano F, Wang X, Bertolotti A, Zhang Y, Chung P, Harding HP, et al. Coupling of stress in the ER to activation of JNK protein kinases by transmembrane protein kinase IRE1. Science. 2000;287(5453):664-6.

34. Zeng H, Guo M, Zhou T, Tan L, Chong CN, Zhang T, et al. An isogenic human ESC platform for functional evaluation of genome-wideassociation-study-identified diabetes genes and drug discovery. Cell Stem Cell. 2016;19(3):326-40.

35. Chen X, Iliopoulos D, Zhang Q, Tang Q, Greenblatt MB, Hatziapostolou $\mathrm{M}$, et al. XBP1 promotes triple-negative breast cancer by controlling the HIF1alpha pathway. Nature. 2014;508(7494):103-7.

36. Condamine T, Kumar V, Ramachandran IR, Youn Jl, Celis E, Finnberg N, et al. ER stress regulates myeloid-derived suppressor cell fate through TRAIL-R-mediated apoptosis. J Clin Invest. 2014;124(6):2626-39.
37. Yan D, Wang HW, Bowman RL, Joyce JA. STAT3 and STAT6 Signaling pathways synergize to promote cathepsin secretion from macrophages via IRE1alpha activation. Cell Rep. 2016;16(11):2914-27.

38. Song M, Sandoval TA, Chae CS, Chopra S, Tan C, Rutkowski MR, et al. IRE1alpha-XBP1 controls T cell function in ovarian cancer by regulating mitochondrial activity. Nature. 2018;562(7727):423-8.

39. Dong H, Adams NM, XU Y, Cao J, Allan DSJ, Carlyle JR, et al. The IRE1 endoplasmic reticulum stress sensor activates natural killer cell immunity in part by regulating c-Myc. Nat Immunol. 2019;20(7):865-78.

40. Sheng X, Nenseth HZ, Qu S, Kuzu OF, Frahnow T, Simon L, et al. IRE1alpha-XBP1s pathway promotes prostate cancer by activating c-MYC signaling. Nat Commun. 2019;10(1):323.

41. Zhao N, Cao J, Xu L, Tang Q, Dobrolecki LE, Lv X, et al. Pharmacological targeting of MYC-regulated IRE1/XBP1 pathway suppresses MYC-driven breast cancer. J Clin Invest. 2018;128(4):1283-99.

42. Sun $Y$, Jiang F, Pan $Y$, Chen $X$, Chen J, Wang Y, et al. XBP1 promotes tumor invasion and is associated with poor prognosis in oral squamous cell carcinoma. Oncol Rep. 2018;40(2):988-98.

43. Wu S, Du R, Gao C, Kang J, Wen J, Sun T. The role of XBP1s in the metastasis and prognosis of hepatocellular carcinoma. Biochem Biophys Res Commun. 2018;500(3):530-7.

44. Yang J, Cheng D, Zhou S, Zhu B, Hu T, Yang Q. Overexpression of X-Box Binding Protein 1 (XBP1) Correlates to Poor Prognosis and Up-Regulation of PI3K/mTOR in Human Osteosarcoma. Int J Mol Sci. 2015;16(12):28635-46.

45. Bagratuni T, Wu P, Gonzalez de Castro D, Davenport EL, Dickens NJ, Walker BA, et al. XBP1s levels are implicated in the biology and outcome of myeloma mediating different clinical outcomes to thalidomide-based treatments. Blood. 2010;116(2):250-3.

46. Gambella M, Rocci A, Passera R, Gay F, Omede P, Crippa C, et al. High $\mathrm{XBP} 1$ expression is a marker of better outcome in multiple myeloma patients treated with bortezomib. Haematologica. 2014;99(2):e14-16.

47. Ming J, Ruan S, Wang M, Ye D, Fan N, Meng Q, et al. A novel chemical, STF-083010, reverses tamoxifen-related drug resistance in breast cancer by inhibiting IRE1/XBP1. Oncotarget. 2015;6(38):40692-703.

48. Rozpedek W, Pytel D, Mucha B, Leszczynska H, Diehl JA, Majsterek I. The role of the PERK/eIF2alpha/ATF4/CHOP Signaling Pathway In Tumor Progression During Endoplasmic Reticulum Stress. Curr Mol Med. 2016;16(6):533-44.

49. Cabrera E, Hernandez-Perez S, Koundrioukoff S, Debatisse M, Kim D, Smolka MB, et al. PERK inhibits DNA replication during the unfolded protein response via claspin and Chk1. Oncogene. 2017;36(5):678-86.

50. Harding HP, Zhang Y, Scheuner D, Chen JJ, Kaufman RJ, Ron D. Ppp1r15 gene knockout reveals an essential role for translation initiation factor 2 alpha (elF2alpha) dephosphorylation in mammalian development. Proc Natl Acad Sci USA. 2009;106(6):1832-7.

51. Qiao Q, Sun C, Han C, Han N, Zhang M, Li G. Endoplasmic reticulum stress pathway PERK-elF2alpha confers radioresistance in oropharyngeal carcinoma by activating NF-kappaB. Cancer Sci. 2017;108(7):1421-31.

52. Cullinan SB, Zhang D, Hannink M, Arvisais E, Kaufman RJ, Diehl JA. Nrf2 is a direct PERK substrate and effector of PERK-dependent cell survival. Mol Cell Biol. 2003;23(20):7198-209.

53. Salaroglio IC, Panada E, Moiso E, Buondonno I, Provero P, Rubinstein $M$, et al. PERK induces resistance to cell death elicited by endoplasmic reticulum stress and chemotherapy. Mol Cancer. 2017;16(1):91.

54. Hou X, Liu Y, Liu H, Chen X, Liu M, Che H, et al. PERK silence inhibits glioma cell growth under low glucose stress by blockage of p-AKT and subsequent HK2's mitochondria translocation. Sci Rep. 2015;5:9065.

55. Rouschop KM, van den Beucken T, Dubois L, Niessen H, Bussink J, Savelkouls K, et al. The unfolded protein response protects human tumor cells during hypoxia through regulation of the autophagy genes MAP1LC3B and ATG5. J Clin Invest. 2010;120(1):127-41.

56. Bu Y, Diehl JA. PERK integrates oncogenic signaling and cell survival during cancer development. J Cell Physiol. 2016;231(10):2088-96.

57. Feng YX, Jin DX, Sokol ES, Reinhardt F, Miller DH, Gupta PB. Cancer-specific PERK signaling drives invasion and metastasis through CREB3L1. Nat Commun. 2017;8(1):1079.

58. Zhu H, Chen X, Chen B, Chen B, Song W, Sun D, et al. Activating transcription factor 4 promotes esophageal squamous cell carcinoma 
invasion and metastasis in mice and is associated with poor prognosis in human patients. PLoS ONE. 2014;9(7):e103882.

59. Alasiri G, Jiramongkol Y, Zona S, Fan LY, Mahmud Z, Gong G, et al. Regulation of PERK expression by FOXO3: a vulnerability of drug-resistant cancer cells. Oncogene. 2019;38(36):6382-98.

60. Hillary RF, FitzGerald U. A lifetime of stress: ATF6 in development and homeostasis. J Biomed Sci. 2018;25(1):48.

61. Limonta P, Moretti RM, Marzagalli M, Fontana F, Raimondi M, Montagnani MM. Role of endoplasmic reticulum stress in the anticancer activity of natural compounds. Int J Mol Sci. 2019;20(4):961.

62. Thuerauf DJ, Marcinko M, Belmont PJ, Glembotski CC. Effects of the isoform-specific characteristics of ATF6 alpha and ATF6 beta on endoplasmic reticulum stress response gene expression and cell viability. J Biol Chem. 2007;282(31):22865-78.

63. Bu LJ, Yu HQ, Fan LL, Li XQ, Wang F, Liu JT, et al. Melatonin, a novel selective ATF-6 inhibitor, induces human hepatoma cell apoptosis through COX-2 downregulation. World J Gastroenterol. 2017;23(6):986-98.

64. Ciavattini A, Delli Carpini G, Serri M, Tozzi A, Leoni F, Di Loreto E, et al. Unfolded protein response, a link between endometrioid ovarian carcinoma and endometriosis: a pilot study. Oncol Lett. 2018;16(4):5449-54.

65. Samanta S, Tamura S, Dubeau L, Mhawech-Fauceglia P, Miyagi Y, Kato H, et al. Clinicopathological significance of endoplasmic reticulum stress proteins in ovarian carcinoma. Sci Rep. 2020;10(1):2160.

66. Yao X, Tu Y, Xu Y, Guo Y, Yao F, Zhang X. Endoplasmic reticulum stressinduced exosomal miR-27a-3p promotes immune escape in breast cancer via regulating PD-L1 expression in macrophages. J Cell Mol Med. 2020;24:9560-73.

67. Schewe DM, Aguirre-Ghiso JA. ATF6alpha-Rheb-mTOR signaling promotes survival of dormant tumor cells in vivo. Proc Natl Acad Sci USA. 2008;105(30):10519-24.

68. Wang L, Zhang Y, Wang W, Zhu Y, Chen Y, Tian B. Gemcitabine treatment induces endoplasmic reticular (ER) stress and subsequently upregulates urokinase plasminogen activator (UPA) to block mitochondrialdependent apoptosis in Panc-1 cancer stem-like cells (CSCS). PLoS ONE. 2017;12(8):e0184110.

69. Liu CY, Hsu CC, Huang TT, Lee CH, Chen JL, Yang SH, et al. ER stressrelated ATF6 upregulates CIP2A and contributes to poor prognosis of colon cancer. Mol Oncol. 2018;12(10):1706-17.

70. Kim JK, Kang KA, Piao MJ, Ryu YS, Han X, Fernando PM, et al. Endoplasmic reticulum stress induces 5 -fluorouracil resistance in human colon cancer cells. Environ Toxicol Pharmacol. 2016;44:128-33.

71. Yarapureddy S, Abril J, Foote J, Kumar S, Asad O, Sharath V, et al. ATF6alpha activation enhances survival against chemotherapy and serves as a prognostic indicator in osteosarcoma. Neoplasia. 2019;21 (6):516-32.

72. Sicari D, Fantuz M, Bellazzo A, Valentino E, Apollonio M, Pontisso I, et al. Mutant p53 improves cancer cells' resistance to endoplasmic reticulum stress by sustaining activation of the UPR regulator ATF6. Oncogene. 2019;38(34):6184-95.

73. Duan Q, Wang X, Gong W, Ni L, Chen C, He X, et al. ER stress negatively modulates the expression of the miR-199a/214 cluster to regulates tumor survival and progression in human hepatocellular cancer. PLoS ONE. 2012;7(2):e31518.

74. Fornari F, Milazzo M, Chieco P, Negrini M, Calin GA, Grazi GL, et al. MiR-199a-3p regulates mTOR and c-Met to influence the doxorubicin sensitivity of human hepatocarcinoma cells. Cancer Res. 2010;70(12):5184-93.

75. Jiang J, Ma B, Li X, Jin W, Han C, Wang L, et al. MiR-1281, a p53-responsive microRNA, impairs the survival of human osteosarcoma cells upon ER stress via targeting USP39. Am J Cancer Res. 2018;8(9):1764-74.

76. Chen Y, Brandizzi F. IRE1: ER stress sensor and cell fate executor. Trends Cell Biol. 2013;23(11):547-55.

77. Upton JP, Wang L, Han D, Wang ES, Huskey NE, Lim L, et al. IRE1 alpha cleaves select microRNAs during ER stress to derepress translation of proapoptotic Caspase-2. Science. 2012;338(6108):818-22

78. Sun H, Lin DC, Guo X, Kharabi Masouleh B, Gery S, Cao Q, et al. Inhibition of IRE1alpha-driven pro-survival pathways is a promising therapeutic application in acute myeloid leukemia. Oncotarget. 2016;7(14):18736-49.

79. Xu Z, Bu Y, Chitnis N, Koumenis C, Fuchs SY, Diehl JA. miR-216b regulation of c-Jun mediates GADD153/CHOP-dependent apoptosis. Nat Commun. 2016;7:11422.
80. Byrd AE, Aragon IV, Brewer JW. MicroRNA-30c-2* limits expression of proadaptive factor XBP1 in the unfolded protein response. J Cell Biol. 2012;196(6):689-98

81. Bu Y, Yoshida A, Chitnis N, Altman BJ, Tameire F, Oran A, et al. A PERKmiR-211 axis suppresses circadian regulators and protein synthesis to promote cancer cell survival. Nat Cell Biol. 2018;20(1):104-15.

82. Kim C, Song HS, Park H, Kim B. Activation of ER stress-dependent miR$216 \mathrm{~b}$ has a critical role in salviamiltiorrhiza ethanol-extract-induced apoptosis in U266 and U937 cells. Int J Mol Sci. 2018;19(4):1240.

83. Jiang HY, Wek RC. GCN2 phosphorylation of elF2alpha activates NFkappaB in response to UV irradiation. Biochem J. 2005;385(Pt 2):371-80.

84. Chitnis NS, Pytel D, Bobrovnikova-Marjon E, Pant D, Zheng H, Maas NL, et al. miR-211 is a prosurvival microRNA that regulates chop expression in a PERK-dependent manner. Mol Cell. 2012;48(3):353-64.

85. Kato M, Wang M, Chen Z, Bhatt K, Oh HJ, Lanting L, et al. An endoplasmic reticulum stress-regulated IncRNA hosting a microRNA megacluster induces early features of diabetic nephropathy. Nat Commun. 2016;7:12864

86. Bhattacharyya S, Vrati S. The Malat1 long non-coding RNA is upregulated by signalling through the PERK axis of unfolded protein response during flavivirus infection. Sci Rep. 2015;5:17794.

87. Jiang X, Li D, Wang G, Liu J, Su X, Yu W, et al. Thapsigargin promotes colorectal cancer cell migration through upregulation of IncRNA MALAT1. Oncol Rep. 2020;43(4):1245-55.

88. Zhang $L$, Wang $Y$, Zhang $L$, Xia $X$, Chao Y, He R, et al. ZBTB7A, a miR-663a target gene, protects osteosarcoma from endoplasmic reticulum stressinduced apoptosis by suppressing LncRNA GAS5 expression. Cancer Lett. 2019;448:105-16.

89. Hetz C. The unfolded protein response: controlling cell fate decisions under ER stress and beyond. Nat Rev Mol Cell Biol. 2012;13(2):89-102.

90. Cao Y, Trillo-Tinoco J, Sierra RA, Anadon C, Dai W, Mohamed E, et al. ER stress-induced mediator C/EBP homologous protein thwarts effector T cell activity in tumors through T-bet repression. Nat Commun. 2019;10(1):1280.

91. Lim HJ, Park MN, Kim C, Kang B, Song HS, Lee H, et al. MiR-657/ATF2 signaling pathway has a critical role in Spatholobus suberectus Dunn extract-induced apoptosis in U266 and U937 cells. Cancers (Basel). 2019:11(2):150.

92. Cha JA, Song HS, Kang B, Park MN, Park KS, Kim SH, et al. miR-211 plays a critical role in Cnidium officinale Makino extract-induced, ROS/ ER stress-mediated apoptosis in U937 and U266 cells. Int J Mol Sci. 2018;19(3):295

93. Tu L, Long X, Song W, Lv Z, Zeng H, Wang T, et al. MiR-34c acts as a tumor suppressor in non-small cell lung cancer by inducing endoplasmic reticulum stress through targeting HMGB1. Onco Targets Ther. 2019;12:5729-39.

94. Siwecka N, Rozpedek W, Pytel D, Wawrzynkiewicz A, Dziki A, Dziki L, et al. Dual role of endoplasmic reticulum stress-mediated unfolded protein response signaling pathway in carcinogenesis. Int J Mol Sci. 2019;20(18):4354

95. Alexaki VI, Javelaud D, Mauviel A. JNK supports survival in melanoma cells by controlling cell cycle arrest and apoptosis. Pigment Cell Melanoma Res. 2008;21(4):429-38.

96. Lei K, Davis RJ. JNK phosphorylation of Bim-related members of the Bcl2 family induces Bax-dependent apoptosis. Proc Natl Acad Sci USA. 2003;100(5):2432-7.

97. Brown M, Strudwick N, Suwara M, Sutcliffe LK, Mihai AD, Ali AA, et al. An initial phase of JNK activation inhibits cell death early in the endoplasmic reticulum stress response. J Cell Sci. 2016;129(12):2317-28.

98. Xu K, Han B, Bai Y, Ma XY, Ji ZN, Xiong Y, et al. MiR-451a suppressing BAP31 can inhibit proliferation and increase apoptosis through inducing ER stress in colorectal cancer. Cell Death Dis. 2019;10(3):152.

99. Papaioannou A, Chevet E. Driving cancer tumorigenesis and metastasis through UPR signaling. Curr Top Microbiol Immunol. 2018;414:159-92.

100. Feng YX, Sokol ES, Del Vecchio CA, Sanduja S, Claessen JH, Proia TA, et al. Epithelial-to-mesenchymal transition activates PERK-elF2alpha and sensitizes cells to endoplasmic reticulum stress. Cancer Discov. 2014:4(6):702-15.

101. Shah PP, Dupre TV, Siskind LJ, Beverly LJ. Common cytotoxic chemotherapeutics induce epithelial-mesenchymal transition (EMT) downstream of ER stress. Oncotarget. 2017;8(14):22625-39. 
102. Clarke HJ, Chambers JE, Liniker E, Marciniak SJ. Endoplasmic reticulum stress in malignancy. Cancer Cell. 2014;25(5):563-73.

103. Rankin EB, Giaccia AJ. Hypoxic control of metastasis. Science. 2016;352(6282):175-80.

104. Mujcic H, Rzymski T, Rouschop KM, Koritzinsky M, Milani M, Harris $A L$, et al. Hypoxic activation of the unfolded protein response (UPR) induces expression of the metastasis-associated gene LAMP3. Radiother Oncol. 2009;92(3):450-9.

105. Mujcic H, Nagelkerke A, Rouschop KM, Chung S, Chaudary N, Span PN et al. Hypoxic activation of the PERK/elF2alpha arm of the unfolded protein response promotes metastasis through induction of LAMP3. Clin Cancer Res. 2013;19(22):6126-37.

106. Zheng H, Wu Y, Guo T, Liu F, Xu Y, Cai S. Hypoxia Induces Growth Differentiation Factor 15 to Promote the Metastasis of Colorectal Cancer via PERK-elF2alpha Signaling. Biomed Res Int. 2020;2020:5958272.

107. Romero-Ramirez L, Cao H, Nelson D, Hammond E, Lee AH, Yoshida $\mathrm{H}$, et al. XBP1 is essential for survival under hypoxic conditions and is required for tumor growth. Cancer Res. 2004;64(17):5943-7.

108. Wu H, Li J, Guo E, Luo S, Wang G. MiR-410 acts as a tumor suppressor in estrogen receptor-positive breast cancer cells by directly targeting ERLIN2 via the ERS pathway. Cell Physiol Biochem. 2018;48(2):461-74.

109. Jeon YJ, Kim T, Park D, Nuovo GJ, Rhee S, Joshi P, et al. miRNA-mediated TUSC3 deficiency enhances UPR and ERAD to promote metastatic potential of NSCLC. Nat Commun. 2018;9(1):5110.

110. Rodvold JJ, Chiu KT, Hiramatsu N, Nussbacher JK, Galimberti V, Mahadevan NR, et al. Intercellular transmission of the unfolded protein response promotes survival and drug resistance in cancer cells. Sci Signal. 2017;10:482.

111. Mahadevan NR, Rodvold J, Sepulveda H, Rossi S, Drew AF, Zanetti M. Transmission of endoplasmic reticulum stress and pro-inflammation from tumor cells to myeloid cells. Proc Natl Acad Sci USA. 2011;108(16):6561-6.

112. Doron B, Abdelhamed S, Butler JT, Hashmi SK, Horton TM, Kurre P. Transmissible ER stress reconfigures the AML bone marrow compartment. Leukemia. 2019;33(4):918-30.

113. Wei S, Peng L, Yang J, Sang H, Jin D, Li X, et al. Exosomal transfer of miR-15b-3p enhances tumorigenesis and malignant transformation through the DYNLT1/Caspase-3/Caspase-9 signaling pathway in gastric cancer. J Exp Clin Cancer Res. 2020;39(1):32.

114. Zanetti M. Cell-extrinsic effects of the tumor unfolded protein response on myeloid cells and T cells. Ann N Y Acad Sci. 2013;1284:6-11.

115. Liu J, Fan L, Yu H, Zhang J, He Y, Feng D, et al. Endoplasmic reticulum stress causes liver cancer cells to release exosomal miR-23a-3p and up-regulate programmed death ligand 1 expression in macrophages. Hepatology. 2019;70(1):241-58.

116. Du L, Li YJ, Fakih M, Wiatrek RL, Duldulao M, Chen Z, et al. Role of SUMO activating enzyme in cancer stem cell maintenance and self-renewal. Nat Commun. 2016;7:12326

117. Wang J, Wang P, Zhang T, Gao Z, Wang J, Feng M, et al. Molecular mechanisms for stemness maintenance of acute myeloid leukemia stem cells. Blood Sci. 2019;1(1):77-83.

118. Kumar D, Gorain M, Kundu G, Kundu GC. Therapeutic implications of cellular and molecular biology of cancer stem cells in melanoma. Mol Cancer. 2017;16(1):7.

119. La Porta CA. Mechanism of drug sensitivity and resistance in melanoma. Curr Cancer Drug Targets. 2009;9(3):391-7.

120. Lin J, Zhang D, Fan Y, Chao Y, Chang J, Li N, et al. Regulation of cancer stem cell self-renewal by HOXB9 antagonizes endoplasmic reticulum stress-induced melanoma cell apoptosis via the miR-765-FOXA2 axis. Invest Dermatol. 2018;138(7):1609-19.

121. Zhang $Y$, Wu J, Jing H, Huang G, Sun Z, Xu S. Long noncoding RNA MEG3 inhibits breast cancer growth via upregulating endoplasmic reticulum stress and activating NF-kappaB and p53. J Cell Biochem. 2019;120(4):6789-97.

122. Huang ZL, Chen RP, Zhou XT, Zhan HL, Hu MM, Liu B, et al. Long non-coding RNA MEG3 induces cell apoptosis in esophageal cancer through endoplasmic reticulum stress. Oncol Rep. 2017;37(5):3093-9.

123. Chen RP, Huang ZL, Liu LX, Xiang MQ, Li GP, Feng JL, et al. Involvement of endoplasmic reticulum stress and p53 in IncRNA MEG3induced human hepatoma HepG2 cell apoptosis. Oncol Rep. 2016;36(3):1649-57.
124. Pan X, Cao YM, Liu JH, Ding J, Xie XY, Cao PG. MEG3 induces cervical carcinoma cells' apoptosis through endoplasmic reticulum stress by miR-7-5p/STC1 axis. Cancer Biother Radiopharm. 2020. https://doi. org/10.1089/cbr.2019.3344.

125. Wang G, Ye Q, Ning S, Yang Z, Chen Y, Zhang L, et al. LncRNA MEG3 promotes endoplasmic reticulum stress and suppresses proliferation and invasion of colorectal carcinoma cells through the MEG3/ miR-103a-3p/PDHB ceRNA pathway. Neoplasma. 2020. https://doi. org/10.4149/neo_2020_200813N858.

126. Bao D, Yuan RX, Zhang Y. Effects of IncRNA MEG3 on proliferation and apoptosis of gallbladder cancer cells through regulating NF-KB signaling pathway. Eur Rev Med Pharmacol Sci. 2020;24(12):6632-8.

127. Ding Z, Kang J, Yang Y. Long non-coding RNA CASC2 enhances irradiation-induced endoplasmic reticulum stress in NSCLC cells through PERK signaling. 3 Biotech. 2020;10(10):449.

128. Huang ZH, Zhang SX, Wang C, Zhao R, Qiao J, Bai WQ, et al. Downregulated long non-coding RNA FOXD3-AS1 promotes endoplasmic reticulum stress-induced apoptosis by inhibiting $R C N 1$ via let-7e-5p in nasopharyngeal carcinoma. Am J Physiol Cell Physiol. 2020. https ://doi.org/10.1152/ajpcell.00352.2019.

129. Jin S, Yang X, Li J, Yang W, Ma H, Zhang Z. p53-targeted lincRNAp21 acts as a tumor suppressor by inhibiting JAK2/STAT3 signaling pathways in head and neck squamous cell carcinoma. Mol Cancer. 2019;18(1):38.

130. Chen L, Yuan D, Yang Y, Ren M. LincRNA-p21 enhances the sensitivity of radiotherapy for gastric cancer by targeting the $\beta$-catenin signaling pathway. J Cell Biochem. 2019;120(4):6178-87.

131. Shi YH, Ding ZB, Zhou J, Hui B, Shi GM, Ke AW, et al. Targeting autophagy enhances sorafenib lethality for hepatocellular carcinoma via ER stress-related apoptosis. Autophagy. 2011;7(10):1159-72.

132. Yang N, Fu Y, Zhang H, Sima H, Zhu N, Yang G. LincRNA-p21 activates endoplasmic reticulum stress and inhibits hepatocellular carcinoma. Oncotarget. 2015;6(29):28151-63.

133. Zhou K, Ou Q, Wang G, Zhang W, Hao Y, Li W. High long non-coding RNA NORAD expression predicts poor prognosis and promotes breast cancer progression by regulating TGF- $\beta$ pathway. Cancer Cell Int. 2019;19:63.

134. Wan Y, Yao Z, Chen W, Li D. The IncRNA NORAD/miR-520a-3p facilitates malignancy in non-small cell lung cancer via PI3k/Akt/mTOR signaling pathway. Onco Targets Ther. 2020;13:1533-44.

135. Tian Q, Yan X, Yang L, Liu Z, Yuan Z, Shen Z, et al. IncRNA NORAD promotes hepatocellular carcinoma progression via regulating miR144-3p/SEPT2. Am J Transl Res. 2020;12(5):2257-66.

136. Chen Y, Cao K, Li J, Wang A, Sun L, Tang J, et al. Overexpression of long non-coding RNA NORAD promotes invasion and migration in malignant melanoma via regulating the MIR-205-EGLN2 pathway. Cancer Med. 2019;8(4):1744-54.

137. Li Y, Ding $X$, Xiu S, Du G, Liu Y. LnCRNA NEAT1 promotes proliferation, migration and invasion via regulating miR-296-5p/CNN2 axis in hepatocellular carcinoma cells. Onco Targets Ther. 2019;12:9887-97.

138. Yang F, Tang Z, Duan A, Yi B, Shen N, Bo Z, et al. Long noncoding RNA NEAT1 upregulates survivin and facilitates gallbladder cancer progression by sponging microRNA-335. Onco Targets Ther. 2020;13:2357-67.

139. Gao M, Liu L, Zhang D, Yang Y, Chang Z. Long non-coding RNA NEAT1 serves as sponge for miR-365a-3p to promote gastric cancer progression via regulating ABCC4. Onco Targets Ther. 2020;13:3977-85.

140. Zhuang ST, Cai YJ, Liu HP, Qin Y, Wen JF. LncRNA NEAT1/miR-185-5p/ IGF2 axis regulates the invasion and migration of colon cancer. Mol Genet Genomic Med. 2020;8(4):e1125.

141. Geng W, Guo X, Zhang L, Ma Y, Wang L, Liu Z, et al. Resveratrol inhibits proliferation, migration and invasion of multiple myeloma cells via NEAT1-mediated Wnt/beta-catenin signaling pathway. Biomed Pharmacother. 2018;107:484-94.

142. Tang GH, Chen X, Ding JC, Du J, Lin XT, Xia L, et al. LncRNA LUCRC regulates colorectal cancer cell growth and tumorigenesis by targeting endoplasmic reticulum stress response. Front Genet. 2019:10:1409.

143. Wang C, Li Y, Yan S, Wang H, Shao X, Xiao M, et al. Interactome analysis reveals that IncRNA HULC promotes aerobic glycolysis through LDHA and PKM2. Nat Commun. 2020;11(1):3162. 
144. Liu J, Liu ZX, Wu QN, Lu YX, Wong CW, Miao L, et al. Long noncoding RNA AGPG regulates PFKFB3-mediated tumor glycolytic reprogramming. Nat Commun. 2020;11(1):1507.

145. Wang $X$, Chen $K$, Zhao Z. LncRNA OR3A4 regulated the growth of osteosarcoma cells by modulating the miR-1207-5p/G6PD signaling. Onco Targets Ther. 2020;13:3117-28.

146. Vo JN, Cieslik M, Zhang Y, Shukla S, Xiao L, Zhang Y, et al. The landscape of circular RNA in cancer. Cell. 2019;176(4):869-881.e813.

147. Chen B, Huang S. Circular RNA: An emerging non-coding RNA as a regulator and biomarker in cancer. Cancer Lett. 2018;418:41-50.

148. Zhou N, Qiao H, Zeng M, Yang L, Zhou Y, Guan Q. Circ_002117 binds to microRNA-370 and promotes endoplasmic reticulum stress-induced apoptosis in gastric cancer. Cancer Cell Int. 2020;20:465.

149. Gao L, Dou ZC, Ren WH, Li SM, Liang X, Zhi KQ. CircCDR1as upregulates autophagy under hypoxia to promote tumor cell survival via AKT/ ERK $(1 / 2) / m T O R$ signaling pathways in oral squamous cell carcinomas. Cell Death Dis. 2019;10(10):745.

150. Deng W, Fu J, Wang T, Chen JX, Fu LB, Peng W. Hsa_circRNA 101036 acts as tumor-suppressor in oral squamous cell carcinoma cells via inducing endoplasmic reticulum stress. Eur Rev Med Pharmacol Sci. 2020;24(11):6111-21.

151. Lin Y, Wang Z, Liu L, Chen L. Akt is the downstream target of GRP78 in mediating cisplatin resistance in ER stress-tolerant human lung cancer cells. Lung Cancer. 2011;71(3):291-7.

152. Gifford JB, Huang W, Zeleniak AE, Hindoyan A, Wu H, Donahue TR, et al. Expression of GRP78, master regulator of the unfolded protein response, increases chemoresistance in pancreatic ductal adenocarcinoma. Mol Cancer Ther. 2016;15:1043-52.

153. Jiang CC, Mao ZG, Avery-Kiejda KA, Wade M, Hersey P, Zhang XD. Glucose-regulated protein 78 antagonizes cisplatin and adriamycin in human melanoma cells. Carcinogenesis. 2009;30:197-204.

154. Bailly C, Waring MJ. Pharmacological effectors of GRP78 chaperone in cancers. Biochem Pharmacol. 2019;163:269-78.

155. Aguirre-Ghiso JA. Models, mechanisms and clinical evidence for cancer dormancy. Nat Rev Cancer. 2007;7(11):834-46.

156. Brewer JW, Diehl JA. PERK mediates cell-cycle exit during the mammalian unfolded protein response. Proc Natl Acad Sci USA. 2000;97(23):12625-30.

157. Recasens A, Munoz L. Targeting cancer cell dormancy. Trends Pharmacol Sci. 2019;40(2):128-41

158. Ranganathan AC, Zhang L, Adam AP, Aguirre-Ghiso JA. Functional coupling of p38-induced up-regulation of BiP and activation of RNAdependent protein kinase-like endoplasmic reticulum kinase to drug resistance of dormant carcinoma cells. Cancer Res. 2006;66(3):1702-11.

159. Dauer P, Sharma NS, Gupta VK, Durden B, Hadad R, Banerjee S, et al. ER stress sensor, glucose regulatory protein 78 (GRP78) regulates redox status in pancreatic cancer thereby maintaining "stemness." Cell Death Dis. 2019;10(2):132.

160. Borjan B, Kern J, Steiner N, Gunsilius E, Wolf D, Untergasser G. Spliced XBP1 levels determine sensitivity of multiple myeloma cells to proteasome inhibitor bortezomib independent of the unfolded protein response mediator GRP78. Front Oncol. 2019;9:1530.

161. Terai H, Kitajima S, Potter DS, Matsui Y, Quiceno LG, Chen T, et al. ER stress signaling promotes the survival of cancer "persister cells" tolerant to EGFR tyrosine kinase inhibitors. Cancer Res. 2018;78(4):1044-57.

162. Jiao X, Qian X, Wu L, Li B, Wang Y, Kong X, et al. microRNA: the impact on cancer stemness and therapeutic resistance. Cells. 2019;9(1):29.

163. Jia Y, Liu W, Zhan HE, Yi XP, Liang H, Zheng QL, et al. Roles of hsamiR-12462 and SLC9A1 in acute myeloid leukemia. J Hematol Oncol. 2020;13(1):101.

164. Wang HW, Zhan HE, Jiang XY, Jin LL, Zhao TM, Xie SR, et al. A novel miRNA restores the chemosensitivity of AML cells through targeting FosB. Front Med. 2020. https://doi.org/10.3389/fmed.2020.582923.

165. Ke X, Yuan Y, Guo C, Yang Y, Pu Q, Hu X, et al. MiR-410 induces stemness by inhibiting Gsk3beta but upregulating beta-catenin in non-small cells lung cancer. Oncotarget. 2017:8(7):11356-71.

166. Koh H, Park H, Chandimali N, Huynh DL, Zhang JJ, Ghosh M, et al. MicroRNA-128 suppresses paclitaxel-resistant lung cancer by inhibiting MUC1-C and BMl-1 in cancer stem cells. Oncotarget. 2017;8(66):110540-51.
167. Yang F, Zhang L, Wang F, Wang Y, Huo XS, Yin YX, et al. Modulation of the unfolded protein response is the core of microRNA-122-involved sensitivity to chemotherapy in hepatocellular carcinoma. Neoplasia. 2011;13(7):590-600.

168. Nishimura N, Radwan MO, Amano M, Endo S, Fujii E, Hayashi H, et al. Novel p97/NCP inhibitor induces endoplasmic reticulum stress and apoptosis in both bortezomib-sensitive and -resistant multiple myeloma cells. Cancer Sci. 2019;110(10):3275-87.

169. Ma YY, Di ZM, Cao Q, Xu WS, Bi SX, Yu JS, et al. Xanthatin induces glioma cell apoptosis and inhibits tumor growth via activating endoplasmic reticulum stress-dependent CHOP pathway. Acta Pharmacol Sin. 2020:41(3):404-14.

170. Di S, Fan C, Ma Z, Li M, Guo K, Han D, et al. PERK/elF-2alpha/CHOP pathway dependent ROS generation mediates butein-induced nonsmall-cell lung cancer apoptosis and G2/M phase arrest. Int J Biol Sci. 2019;15(8):1637-53

171. Tan W, Liao Y, Qiu Y, Liu H, Tan D, Wu T, et al. miRNA 146a promotes chemotherapy resistance in lung cancer cells by targeting DNA damage inducible transcript 3 (CHOP). Cancer Lett. 2018;428:55-68.

172. Gan PP, Zhou YY, Zhong MZ, Peng Y, Li L, Li JH. Endoplasmic reticulum stress promotes autophagy and apoptosis and reduces chemotherapy resistance in mutant p53 lung cancer cells. Cell Physiol Biochem. 2017;44(1):133-51.

173. Yu T, Yu HR, Sun JY, Zhao Z, Li S, Zhang XF, et al. miR-1271 inhibits ERalpha expression and confers letrozole resistance in breast cancer. Oncotarget. 2017;8(63):107134-48.

174. Kong F, Zou H, Liu X, He J, Zheng Y, Xiong L, et al. miR-7112-3p targets PERK to regulate the endoplasmic reticulum stress pathway and apoptosis induced by photodynamic therapy in colorectal cancer CX-1 cells. Photodiagnosis Photodyn Ther. 2020;29:101663.

175. Yao X, Tu Y, Xu Y, Guo Y, Yao F, Zhang X. Endoplasmic reticulum stress confers 5 -fluorouracil resistance in breast cancer cell via the GRP78/OCT4/IncRNA MIAT/AKT pathway. Am J Cancer Res. 2020b;10(3):838-55.

176. Kwon D, Koh J, Kim S, Go H, Min HS, Kim YA, et al. Overexpression of endoplasmic reticulum stress-related proteins, XBP1s and GRP78, predicts poor prognosis in pulmonary adenocarcinoma. Lung Cancer. 2018;122:131-7.

177. Lee HY, Jung JH, Cho HM, Kim SH, Lee KM, Kim HJ, et al. GRP78 protein expression as prognostic values in neoadjuvant chemoradiotherapy and laparoscopic surgery for locally advanced rectal cancer. Cancer Res Treat. 2015:47(4):804-12.

178. Axten JM, Medina JR, Feng Y, Shu A, Romeril SP, Grant SW, et al. Discovery of 7-methyl-5-(1-\{[3-(trifluoromethyl)phenyl]acetyl\}2,3-dihydro-1H-indol-5-yl)-7H-pyrrolo[2,3-d]pyrimidin-4-amine (GSK2606414), a potent and selective first-in-class inhibitor of protein kinase $R(P K R)$-like endoplasmic reticulum kinase (PERK). J Med Chem. 2012;55(16):7193-207.

179. Axten JM, Romeril SP, Shu A, Ralph J, Medina JR, Feng Y, et al. Discovery of GSK2656157: an optimized PERK inhibitor selected for preclinical development. ACS Med Chem Lett. 2013:4(10):964-8.

180. Higa A, Taouji S, Lhomond S, Jensen D, Fernandez-Zapico ME, Simpson $\mathrm{JC}$, et al. Endoplasmic reticulum stress-activated transcription factor ATF6a requires the disulfide isomerase PDIA5 to modulate chemoresistance. Mol Cell Biol. 2014;34(10):1839-49.

181. Mimura N, Fulciniti M, Gorgun G, Tai YT, Cirstea D, Santo L, et al. Blockade of XBP1 splicing by inhibition of IRE1 a is a promising therapeutic option in multiple myeloma. Blood. 2012;119(24):5772-81.

182. Papandreou I, Denko NC, Olson M, Van Melckebeke H, Lust S, Tam $A$, et al. Identification of an Irelalpha endonuclease specific inhibitor with cytotoxic activity against human multiple myeloma. Blood. 2011:117(4):1311-4

183. Lee DH, Jung Jung Y, Koh D, Lim Y, Lee YH, Shin SY. A synthetic chalcone, 2'-hydroxy-2,3,5'-trimethoxychalcone triggers unfolded protein response-mediated apoptosis in breast cancer cells. Cancer Lett. 2016:372(1):1-9.

184. Huang Y, Liu J, Fan L, Wang F, Yu H, Wei W, et al. miR-663 overexpression induced by endoplasmic reticulum stress modulates hepatocellular carcinoma cell apoptosis via transforming growth factor beta 1. Onco Targets Ther. 2016;9:1623-33. 
185. Dai R, Li J, Liu Y, Yan D, Chen S, Duan C, et al. miR-221/222 suppression protects against endoplasmic reticulum stress-induced apoptosis via p27(Kip1)- and MEK/ERK-mediated cell cycle regulation. Biol Chem. 2010;391(7):791-801.

186. Bartoszewski R, Brewer JW, Rab A, Crossman DK, Bartoszewska S, Kapoor N, et al. The unfolded protein response (UPR)-activated transcription factor X-box-binding protein 1 (XBP1) induces microRNA-346 expression that targets the human antigen peptide transporter 1 (TAP1) mRNA and governs immune regulatory genes. J Biol Chem. 2011;286(48):41862-70.

187. Quan Y, Song Q, Wang J, Zhao L, LV J, Gong S. MiR-1202 functions as a tumor suppressor in glioma cells by targeting Rab1A. Tumour Biol. 2017;39(4):1010428317697565.

188. Yang Y, Hou N, Wang X, Wang L, Chang S, He K, et al. miR-15b-5p induces endoplasmic reticulum stress and apoptosis in human hepatocellular carcinoma, both in vitro and in vivo, by suppressing Rab1 A. Oncotarget. 2015;6(18):16227-38.

189. Maurel M, Dejeans N, Taouji S, Chevet E, Grosset CF. MicroRNA-

1291-mediated silencing of IRE1 alpha enhances Glypican-3 expression. RNA. 2013;19(6):778-88.

190. Su SF, Chang YW, Andreu-Vieyra C, Fang JY, Yang Z, Han B, et al. miR30d, miR-181a and miR-199a-5p cooperatively suppress the endoplasmic reticulum chaperone and signaling regulator GRP78 in cancer. Oncogene. 2013;32(39):4694-701.

\section{Publisher's Note}

Springer Nature remains neutral with regard to jurisdictional claims in published maps and institutional affiliations.
Ready to submit your research? Choose BMC and benefit from:

- fast, convenient online submission

- thorough peer review by experienced researchers in your field

- rapid publication on acceptance

- support for research data, including large and complex data types

- gold Open Access which fosters wider collaboration and increased citations

- maximum visibility for your research: over 100M website views per year

At BMC, research is always in progress.

Learn more biomedcentral.com/submissions 